\title{
High-Fat Diet-Induced Obesity Causes Sex- Specific Deficits in Adult Hippocampal Neurogenesis in Mice
}

\author{
Lisa S. Robison, Nathan M. Albert, Lauren A. Camargo, Brian M. Anderson, Abigail E. Salinero, David A. \\ Riccio, Charly Abi-Ghanem, Olivia J. Gannon, and Kristen L. Zuloaga
}

https://doi.org/10.1523/ENEURO.0391-19.2019

Department of Neuroscience and Experimental Therapeutics, Albany Medical College, Albany, New York 12208

\begin{abstract}
Adult hippocampal neurogenesis (AHN) is suppressed by high-fat (HF) diet and metabolic disease, including obesity and type 2 diabetes. Deficits in AHN may contribute to cognitive decline and increased risk of dementia and mood disorders, which have higher prevalence in women. However, sex differences in the effects of HF diet/metabolic disease on AHN have yet to be thoroughly investigated. Herein, male and female C57BL/6J mice were fed an HF or control (CON) diet from $\sim 2$ to 6 months of age. After 3 months on the diet, mice were injected with 5-ethynyl-2'-deoxyuridine (EdU) then killed 4 weeks later. Cell proliferation, differentiation/maturation, and survival of new neurons in the dentate gyrus were assessed with immunofluorescence for EdU, Ki67, doublecortin (DCX), and NeuN. CON females had more proliferating cells $\left(\mathrm{Ki}^{+} 7^{+}\right)$and neuroblasts/immature neurons $\left(\mathrm{DCX}^{+}\right)$ compared with CON males; however, HF diet reduced these cells in females to the levels of males. Diet did not affect neurogenesis in males. Further, the numbers of proliferating cells and immature neurons were inversely correlated with both weight gain and glucose intolerance in females only. These effects were robust in the dorsal hippocampus, which supports cognitive processes. Assessment of microglia in the dentate gyrus using immunofluorescence for lba1 and CD68 uncovered sex-specific effects of diet, which may contribute to observed differences in neurogenesis. These findings demonstrate sex-specific effects of HF diet/metabolic disease on $\mathrm{AHN}$, and highlight the potential for targeting neurogenic deficits to treat cognitive decline and reduce the risk of dementia associated with these conditions, particularly in females.
\end{abstract}

Key words: hippocampus; metabolic disorders; microglia; neurogenesis; prediabetes; sex differences

\section{Significance Statement}

Poor diet and metabolic disease, including obesity and type 2 diabetes, are associated with an increased risk of neurodegenerative and neuropsychiatric disorders, including Alzheimer's disease, anxiety, and depression. Impaired adult hippocampal neurogenesis may be one mechanism linking these conditions; however, it is unknown whether there are sex-specific effects of high-fat diet/metabolic disease on neurogenesis, which could underlie the observed sex difference in these conditions (females more adversely affected than males). We report that high-fat diet/metabolic disease impairs cell proliferation and the number of neuroblasts/immature neurons in the dorsal hippocampus, a region that supports cognitive function, in females only. Sex-specific effects of diet on microglia in the subgranular zone were also apparent. 


\section{Introduction}

Neurogenesis involves the proliferation, migration, differentiation, survival, and integration of new neurons into existing circuitry, playing a role in brain plasticity (Christie and Cameron, 2006). One region of the brain in which neurogenesis persists through adulthood in many species, including humans and rodents, is the subgranular zone (SGZ) of the dentate gyrus within the hippocampus (Kempermann et al., 2015). This region can be split along its longitudinal axis into the dorsal hippocampus (septal pole), which is involved in cognitive processes, and the ventral hippocampus (temporal pole), which is involved in emotion processing; these are analogous to the posterior and anterior portions of the hippocampus, respectively, in primates (Fanselow and Dong, 2010). Therefore, adult hippocampal neurogenesis (AHN) plays a role in both cognitive functions, such as learning and memory, and affective processes, including mood regulation and reactivity to stress (Tanti and Belzung, 2013).

Hippocampal atrophy and dysregulated AHN are seen in the brains of patients with neurodegenerative and neuropsychiatric illnesses, including Alzheimer's disease (AD), anxiety, and depression, while animal models of these diseases also exhibit altered neurogenesis (Wang et al., 2003; Cole et al., 2011; Hill et al., 2015; Miller and Hen, 2015; Chan et al., 2016; Unger et al., 2016; MorenoJiménez et al., 2019). Impaired AHN is hypothesized to contribute to symptoms of these conditions, as interventions that promote neurogenesis alleviate symptoms, and medications used to treat these disorders enhance AHN (Santarelli et al., 2003; Jin et al., 2006; Boldrini et al., 2009; Blanchard et al., 2010; Valero et al., 2011; Hill et al., 2015; Richetin et al., 2015; Tapia-Rojas et al., 2016). Therefore, factors that affect AHN also likely influence risk and severity of these diseases. In addition to pharmacological interventions, AHN is altered by environmental factors, including physical activity, stress, and learning (Tanapat et al., 1998; Gould et al., 1999; van Praag et al., 1999). Interestingly, some factors not only influence specific stages of neurogenesis (e.g., proliferation or new neuron survival), but also affect neurogenesis in a subregionand/or sex-specific manner (Westenbroek et al., 2004; Tanti et al., 2012; Tanti et al., 2013; Yagi and Galea, 2019).

Received September 27, 2019; accepted December 1, 2019; First published December 23, 2019.

The authors declare no competing financial interests.

Author contributions: L.S.R. and K.L.Z. designed research; L.S.R., N.M.A., L.A.C., B.M.A., A.E.S., D.A.R., C.A.-G., and O.J.G. performed research; L.S.R., N.M.A., L.A.C., and C.A.-G. analyzed data; L.S.R. wrote the paper.

This research was supported by American Heart Association Scientist Development Grant 12SDG2719002 and National Institute of Neurological Disorders and Stroke-National Institute on Aging Grant R01-NS-110749.

Acknowledgments: We thank Dr. Ashley Kopec for suggestions on the analysis of microglia immunofluorescence.

Correspondence should be addressed to Kristen L. Zuloaga at Zuloagk@amc.edu.

https://doi.org/10.1523/ENEURO.0391-19.2019

Copyright (C) 2020 Robison et al.

This is an open-access article distributed under the terms of the Creative Commons Attribution 4.0 International license, which permits unrestricted use, distribution and reproduction in any medium provided that the original work is properly attributed.
This may contribute to sex differences in the observed prevalence, severity, and rate of cognitive decline seen in dementia and depression, with females being more adversely affected (McPherson et al., 1999; Gutiérrez-Lobos et al., 2002; Irvine et al., 2012; Hebert et al., 2013; Beam et al., 2018; Buckley et al., 2019; Eid et al., 2019).

High-fat (HF) diet and metabolic disease, such as obesity and type 2 diabetes, are associated with dysregulated neurogenesis (Park et al., 2010; Ho et al., 2013; Nam et al., 2016; Nam et al., 2017; Tanokashira et al., 2018; Tang et al., 2019). Poor diet and metabolic disease are also associated with cognitive impairment, increased risk/ severity of Alzheimer's disease, and anxiety and depression (Jacka et al., 2010; Xu et al., 2011; Boitard et al., 2012; Spauwen et al., 2013; Boitard et al., 2014; Knight et al., 2014; Chatterjee et al., 2016; Klein et al., 2016; Zuloaga et al., 2016; Shalev and Arbuckle, 2017). Specifically, overweight/obesity is associated with an increased risk ratio of 1.41 for dementia and odds ratio of 1.27-1.55 for depression (Luppino et al., 2010; Pedditzi et al., 2016). Deficits in neurogenesis may be one mechanism linking poor diet and metabolic disease to an increased risk for dementia and mood disorders (Ho et al., 2013). There is evidence to suggest that metabolically unhealthy women are at greater risk for dementia than men (Chatterjee et al., 2016; Gannon et al., 2019). Additionally, there is a sexspecific association between depression and diabetes, with a significant relationship seen in women only (Demmer et al., 2015). However, little is known in regard to possible sex differences in the effects of HF diet and metabolic disease on neurogenesis that may be mediating these relationships. To our knowledge, no studies to date have determined the effects of HF diet/metabolic disease on the various stages of neurogenesis in a sexand region-specific manner. Herein, we sought to do so using male and female C57BL/6J mice administered an HF diet from $\sim 2$ to 6 months of age, which was previously shown to result in a similar prediabetic phenotype (weight gain and glucose intolerance) in both sexes (Salinero et al., 2018).

\section{Materials and Methods}

\section{Animals and experimental design}

Male and female C57BL/6J mice were purchased from The Jackson Laboratory at $\sim 8$ weeks of age. Mice were group housed (five per cage) at $70-72^{\circ} \mathrm{F}$ and $30-70 \%$ humidity, with a $12 \mathrm{~h}$ light/dark cycle (7:00 A.M. on/7:00 P.M. off). Following 1 week of acclimation on Purina Lab Diet 5P76, mice were split into equal groups by sex and placed on their respective treatment diets ( $n=10 /$ group). Mice received either an $\mathrm{HF}$ diet (60\% fat from lard; 5.24 $\mathrm{kcal} / \mathrm{g}$; D12492, Research Diets) or a control (CON) diet (10\% fat; $3.85 \mathrm{kcal} / \mathrm{g}$; D12450B, Research Diets) and remained on the diet for the remainder of the study (18 weeks). Water was provided ad libitum throughout the entire experiment, and body weight was measured monthly throughout the dietary intervention period. At the end of the study, mice were $\sim 6$ months of age. Following 12 weeks on the diet, mice underwent a glucose tolerance test (GTT), and allowed to recover for 2 weeks before 


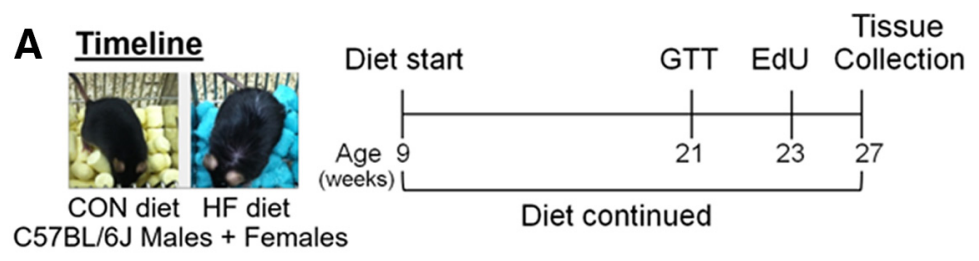

B
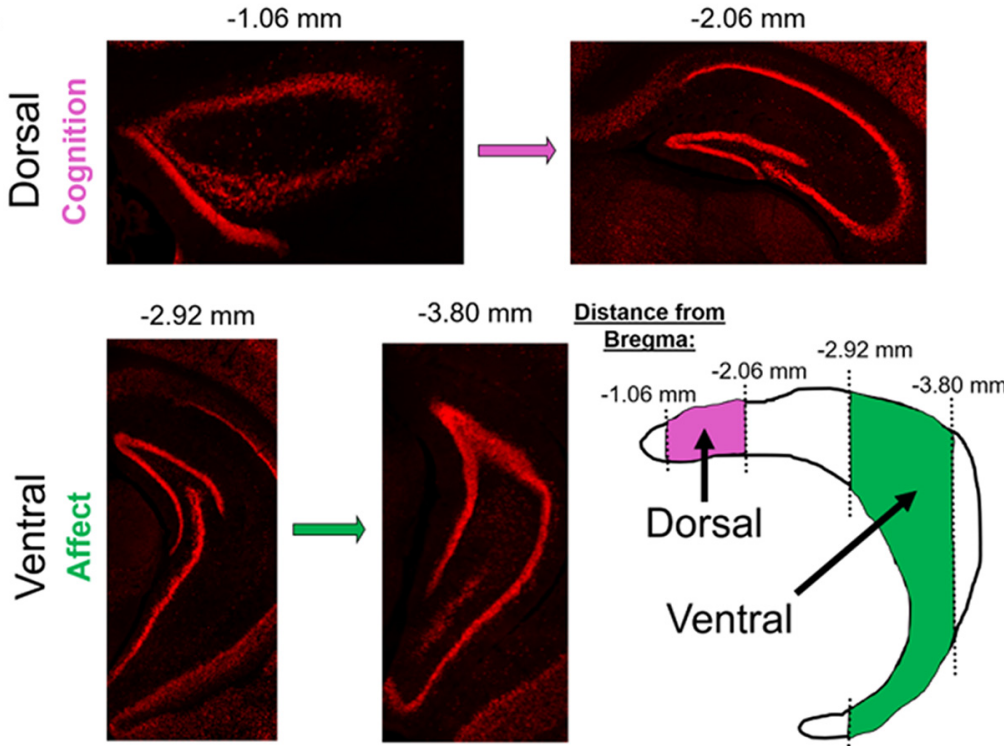

Figure 1. $\boldsymbol{A}$, Timeline of the experiment. Male and female C57BL/6J mice were placed on a CON diet (10\% fat) or an HF diet (60\% fat) at 9 weeks of age, which was continued for the duration of the experiment. After $\sim 3$ months on the diet, mice were subjected to GTT, then injected with EdU $(3 \times) 2$ weeks later. Four weeks after EdU injections, tissue collection was performed. $\boldsymbol{B}$, Breakdown of the hippocampus into dorsal (approximately -1.06 to approximately $-2.06 \mathrm{~mm}$ from bregma) and ventral (approximately -2.92 to approximately $-3.80 \mathrm{~mm}$ from bregma) subregions, which regulate cognitive and affective processes, respectively. Adapted from Tanti and Belzung (2013).

5-ethynyl-2'-deoxyuridine (EdU) injections $(5 \mu \mathrm{l} / \mathrm{g}$ body weight, i.p.; $3 \times / d, 2$ h apart). Four weeks after EdU injections, mice were deeply anesthetized with pentobarbital and transcardially perfused with $0.9 \%$ saline. Brains were rapidly removed and postfixed overnight in $4 \%$ formalin, then cryoprotected in $30 \%$ sucrose for at least $72 \mathrm{~h}$, embedded in optimal cutting temperature compound, and stored at $-80^{\circ} \mathrm{C}$ until cryosectioning. A timeline of the experiment can be seen in Figure $1 A$. All animal procedures were performed in accordance with the regulations of the animal care committee at Albany Medical College.

\section{GTT}

At 12 weeks post-dietary intervention, mice were fasted overnight (16 h), and baseline blood glucose levels in saphenous vein blood were measured by glucometer (OneTouch Verio IQ). Each mouse received an intraperitoneal injection of $2 \mathrm{~g} / \mathrm{kg}$ glucose $(0.2 \mathrm{~g} / \mathrm{ml}$ in Millipore water, sterile filtered), and blood glucose levels were remeasured at $15,30,60,90$, and 120 min post-glucose injection.

\section{Immunohistochemistry}

Brains were sectioned in the coronal plane into six series of $40-\mu \mathrm{m}$-thick sections. Hippocampal sections (ranging from approximately -1.06 to approximately $-3.80 \mathrm{~mm}$ from bregma) from one of these series were used for each panel of immunohistochemistry (IHC), resulting in $\sim 11$ sections analyzed throughout the entirety of the hippocampus. Sections were washed with PBS with $0.01 \%$ sodium azide, permeabilized in $0.3 \%$ Triton $\mathrm{X}-100$ in PBS (TPBS) with sodium azide for $1 \mathrm{~h}$ at room temperature, blocked in $4 \%$ donkey serum in $0.3 \%$ TPBS with sodium azide for $1 \mathrm{~h}$ at room temperature, and incubated at $4^{\circ} \mathrm{C}$ overnight with primary antibodies. For the analysis of neurogenesis, the primary antibodies used included rabbit anti-NeuN (neuronal-specific nuclear protein; 1:1000; ABN78, lot \#3041797, Millipore), guinea pig anti-doublecortin (1:1000; AB2253, lot \#3092504, Millipore), and rabbit anti-Ki67 (1:200; AB15580, lot \#GR3197370-1, Abcam). For evaluation of the activity of microglia/macrophages, the primary antibodies used included goat anti-lba-1 (1:1000; PA5-18039, lot \#TI2638761, Thermo Fisher Scientific), and rat anti-CD68 (1:1000; MCA1957, lot \#1708, Bio-Rad). Fluorescent secondary antibodies (Jackson ImmunoResearch), including Alexa Fluor 405 donkey anti-rabbit (1:300), Alexa Fluor 488 donkey anti-rabbit (1:300), Alexa Fluor 488 donkey anti-guinea pig (1:300), Rhodamine Red-X donkey anti-rat (1:100), and Alexa Fluor 647 donkey anti-goat (1:300) were diluted in blocking buffer and applied at room temperature for $2 \mathrm{~h}$. EdU labeling for newly generated cells was developed using the Click-iT EdU Alexa Fluor 647 Imaging Kit (catalog \#C10340, Thermo Fisher Scientific). 
DAPI (1:1000) was added to secondary antibody solutions in some IHC panels.

\section{Immunohistochemistry analysis}

Images for quantification were taken of the hippocampus at $10 \times$ magnification using the Axio Observer Fluorescent Microscope (Carl Zeiss Microscopy). All immunohistochemistry analyses were performed in coronal sections across the entire hippocampus, noting the distance from bregma for each slice. Measures were taken in the hippocampus of each hemisphere, and left and right values were averaged for each slice. Measures for each slice in a series were averaged to create a "whole" hippocampus average. Additionally, the hippocampus was divided along the dorsoventral axis into dorsal and ventral subregions, as in previous studies examining neurogenesis (Tanti et al., 2012; Yagi et al., 2019). Using coronal sections, the dorsal portion of the hippocampus generally included approximately four sections from approximately -1.06 to approximately $-2.06 \mathrm{~mm}$ from bregma, and the ventral portion of the hippocampus included approximately three sections from approximately -2.92 to approximately $-3.80 \mathrm{~mm}$ from bregma (Fig. 1B). All measurements were performed by an experimenter who was blinded to the identity of the treatment group from which sections came. Representative images are maximum intensity projections of $z$-stacks taken with a confocal microscope (model 880, Carl Zeiss Microscopy) using a $40 \times$ objective .

\section{Quantification of neurogenesis-related measures}

The number of $\mathrm{Ki} 67^{+}, \mathrm{DCX}^{+}, \mathrm{EdU}^{+}, \mathrm{EdU}^{+} / \mathrm{DCX}^{+}$, and $\mathrm{EdU}^{+} / \mathrm{NeuN}^{+}$cells in the entire dentate gyrus were manually counted on every sixth section throughout the entire hippocampus in ZEN software (blue edition, Carl Zeiss Microscopy).

\section{Quantification of microglia-related measures}

Iba1 and CD68 images were thresholded using ZEN (blue edition, Carl Zeiss Microscopy) and ImageJ (NIH) software. Regions of interest (ROls) were drawn around the dentate gyrus and surrounding area of every sixth section using ImageJ (see Fig. 6) to quantify the average area covered by cells positive for each of these antibodies, as well as their colocalization. The "inner" (bordering the hilus) and "outer" ROls of the dentate gyrus were created separately, as microglia activity in these subregions could be differentially regulating neurogenesis (Gemma and Bachstetter, 2013; Rodríguez-Iglesias et al., 2019).

\section{Statistical analysis}

All data are expressed as the mean \pm SEM. Data were analyzed using hypothesis testing by two-way ANOVA (factors: diet and sex). ANOVAs were followed by post hoc tests (Tukey's method). Correlations were run separately for each sex to assess the relationships between metabolic outcomes and measures of neurogenesis and microglia in the subgranular zone of the dentate gyrus. Statistical significance was set at $p<0.05$, and all statistical analyses were performed using GraphPad Prism version 8 software. Additionally, estimation statistics were performed using ESCl modules in Excel (https://thenewstatistics.com/itns/esci/) to report the mean percentage differences between groups, with 95\% confidence intervals. Estimation statistics for significant group differences can be found in text, with all results reported in the Extended Data Fig. 2-1 and 6-1. section.

\section{Results}

\section{High-fat diet results in metabolic impairments in male and female mice}

Differences in metabolic responses to HF diet were assessed in males and females, and were previously reported for these mice (Salinero et al., 2018). All mice on an HF diet gained more weight compared with mice on a CON diet, and this was consistent across sexes. Of note, we found that males and females on an HF diet exhibited similar weight gain (mean \pm SEM: males, $99.30 \pm 5.36 \%$; females, $87.90 \pm 6.57 \%)$ and glucose intolerance [mean area under the curve (AUC) for GTT \pm SEM: males, 57,496 $\pm 2436 \mathrm{mg} / \mathrm{dl}$; females, $52,159 \pm 1424 \mathrm{mg} / \mathrm{dl}$ ] versus low fat-fed mice for weight gain (mean \pm SEM: males, 26.40 $\pm 1.37 \%$; females, $15.60 \pm 2.28 \%$ ) and glucose intolerance (mean AUC during GTT \pm SEM: males, 39,535 \pm $1360 \mathrm{mg} / \mathrm{dl}$; females 29,527 $\pm 1340 \mathrm{mg} / \mathrm{dl}$ ).

\section{High-fat diet decreases cell proliferation in the dorsal hippocampus in females only}

AHN occurs in a number of distinct and tightly regulated phases. In the current study, we assessed sex-dependent effects of HF diet on several stages of AHN in the SGZ of the dentate gyrus. AHN originates from quiescent neural progenitor cells, which give rise to transiently amplifying progenitor cells with high proliferative activity, expanding the number of cells capable of becoming newly born immature neurons (Kempermann et al., 2015). To assess these first stages of neurogenesis, the number of $\mathrm{Ki} 67^{+}$ cells was counted in the dentate gyrus of the hippocampus (Fig. 2). Ki67 is an endogenous protein that is absent in quiescent cells but is expressed throughout all active phases of the cell cycle. Expression of this protein is not limited to cells destined to become neurons, therefore serving as a marker of cell proliferation (Kee et al., 2002). We counted the number of positive cells in sections throughout the entirety of the hippocampus and also quantified the number of cells in the dorsal and ventral subregions, which play a role in cognitive and affective processes, respectively (Fanselow and Dong, 2010; Kheirbek and Hen, 2011). While there were no significant effects of diet or sex in the whole hippocampus or the ventral subregion, group differences were apparent in the number of $\mathrm{Ki}^{+} 7^{+}$cells in the dorsal subregion. Within control mice, females had a greater number of Ki6 $7^{+}$cells compared with males in the dorsal hippocampus $[p=$ 0.0060; mean difference, 57.01\%; $95 \% \mathrm{Cl}(24.42 \%$, $89.59 \%)]$. While diet had no significant effect in males, HF females had fewer $\mathrm{Ki} 7^{+}$cells in the dorsal hippocampus compared with CON females [ $p=0.0047$; mean difference, $-37.21 \%$; 95\% Cl $(-16.46 \%,-57.95 \%)]$. The number of $\mathrm{Ki}^{+} 7^{+}$cells in $\mathrm{HF}$ females was similar to the number of $\mathrm{Ki} 67^{+}$cells in both male groups. 
A

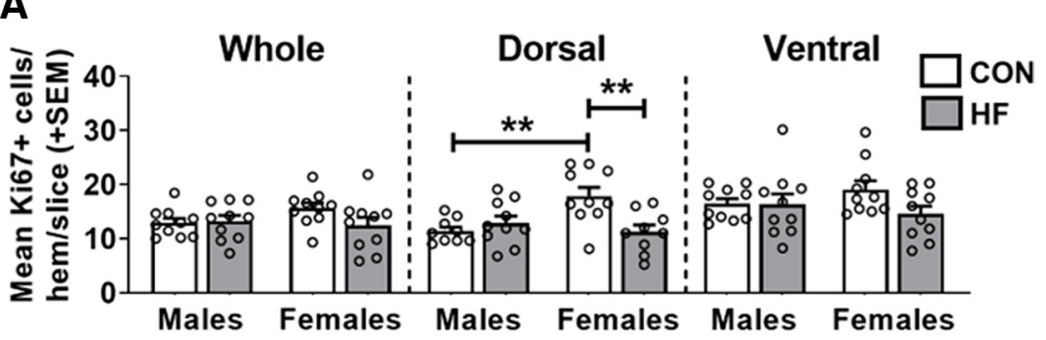

B

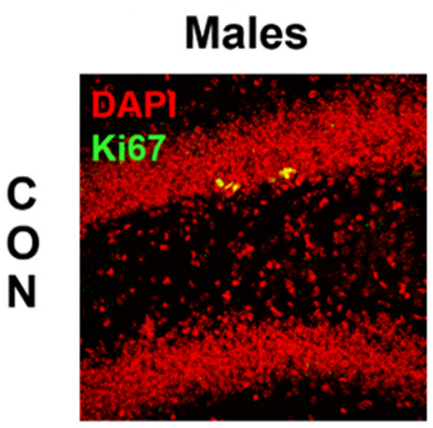

Females
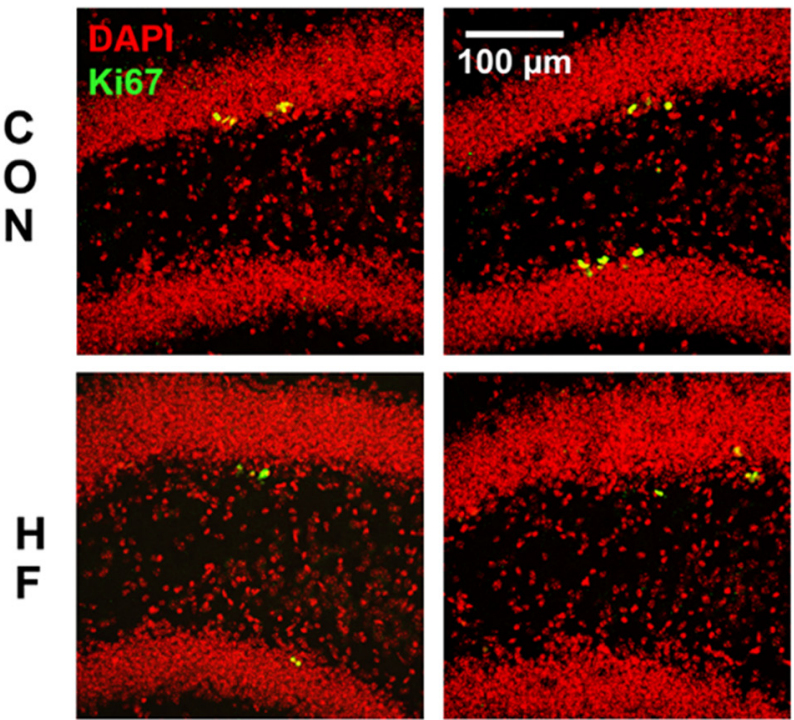

Figure 2. $\boldsymbol{A}$, Cell proliferation in the dentate gyrus, as measured by the mean $( \pm \mathrm{SEM})$ number of Ki67 $7^{+}$cells per hemisphere per 40 $\mu \mathrm{m}$ slice throughout the whole hippocampus, and in the dorsal and ventral subregions. On a control diet, females had a greater number of $\mathrm{Ki} 7^{+}$cells in the dorsal hippocampus compared with males, while HF diet reduced the number of Ki67 $7^{+}$cells in the dorsal hippocampus of females only. $N=10 /$ group. $* * p<0.01$. B, Representative images of Ki67 (green) and DAPI (red) immunostaining in the dorsal hippocampus. Estimation statistics for all neurogenesis-related measures can be seen in Extended Data Figure 2-1.

\section{High-fat diet decreases young/immature neurons in the dorsal hippocampus in females only}

Following the proliferative stages, newborn cells enter a postmitotic maturation phase. During this stage, some cells will have committed to a neuronal fate and begin establishing functional connections (Kempermann et al., 2015). To assess this differentiation/maturation phase, the number of $\mathrm{DCX}^{+}$cells was counted in the dentate gyrus of the hippocampus (Fig. 3). Doublecortin (DCX) is an endogenous protein specific to cells committed to a neuronal fate that aids in the stabilization of microtubules during mitosis. DCX is expressed in new neurons starting at $\sim 4$ $\mathrm{d}$ after birth until approximately $\geq 4$ weeks in mice (Snyder et al., 2009), therefore serving as a marker of neuroblasts/ immature neurons (von Bohlen und Halbach, 2011). Within CON mice, females had a greater number of $\mathrm{DCX}^{+}$ cells compared with males in the whole hippocampus [p $=0.0289$; mean difference, $42.99 \% ; 95 \% \mathrm{Cl}(13.18 \%$, $72.80 \%)]$ and dorsal subregion $(p=0.0012$; mean difference, 67.15\%; 95\% Cl (34.05\%, 100.26\%)]. While diet had no significant effect in males, HF females had fewer $\mathrm{DCX}^{+}$cells in the dorsal subregion compared with CON females $(p=0.0011$; mean difference, $-41.55 \% ; 95 \% \mathrm{Cl}$ $(-21.21 \%,-61.90 \%)]$. The number of $\mathrm{DCX}^{+}$cells in $\mathrm{HF}$ females was therefore similar to the number of $\mathrm{DCX}^{+}$cells in both male groups. There were no significant effects of diet or sex in the ventral subregion of the hippocampus.

\section{Diet has no effect on maturation and survival of newly born neurons in the hippocampus}

Most newborn cells undergo apoptosis before reaching maturity (Kempermann et al., 2015); therefore, it is important to quantify not only how many new cells are produced, but also how many survive and become mature neurons. EdU is a thymidine analog, incorporated during DNA synthesis (S phase of mitosis), serving as an exogenous marker of cell proliferation (Buck et al., 2008). Mice were injected with EdU 4 weeks before euthanasia to determine the effects of sex and diet on newborn cell survival. EdU is not cell type-specific; therefore, we attempted to determine cell type by co-labeling with antibodies against DCX and NeuN. NeuN is an endogenous nuclear protein expressed by mature neurons (von Bohlen und Halbach, 2011). Maturation and survival of newly born neurons in the dentate gyrus was assessed by counting the number of cells that were $\mathrm{EdU}^{+}$(newly born cells of any type), $\mathrm{EdU}^{+} / \mathrm{DCX}^{+}$(newly born cells that began differentiating into neurons but remain in an immature 


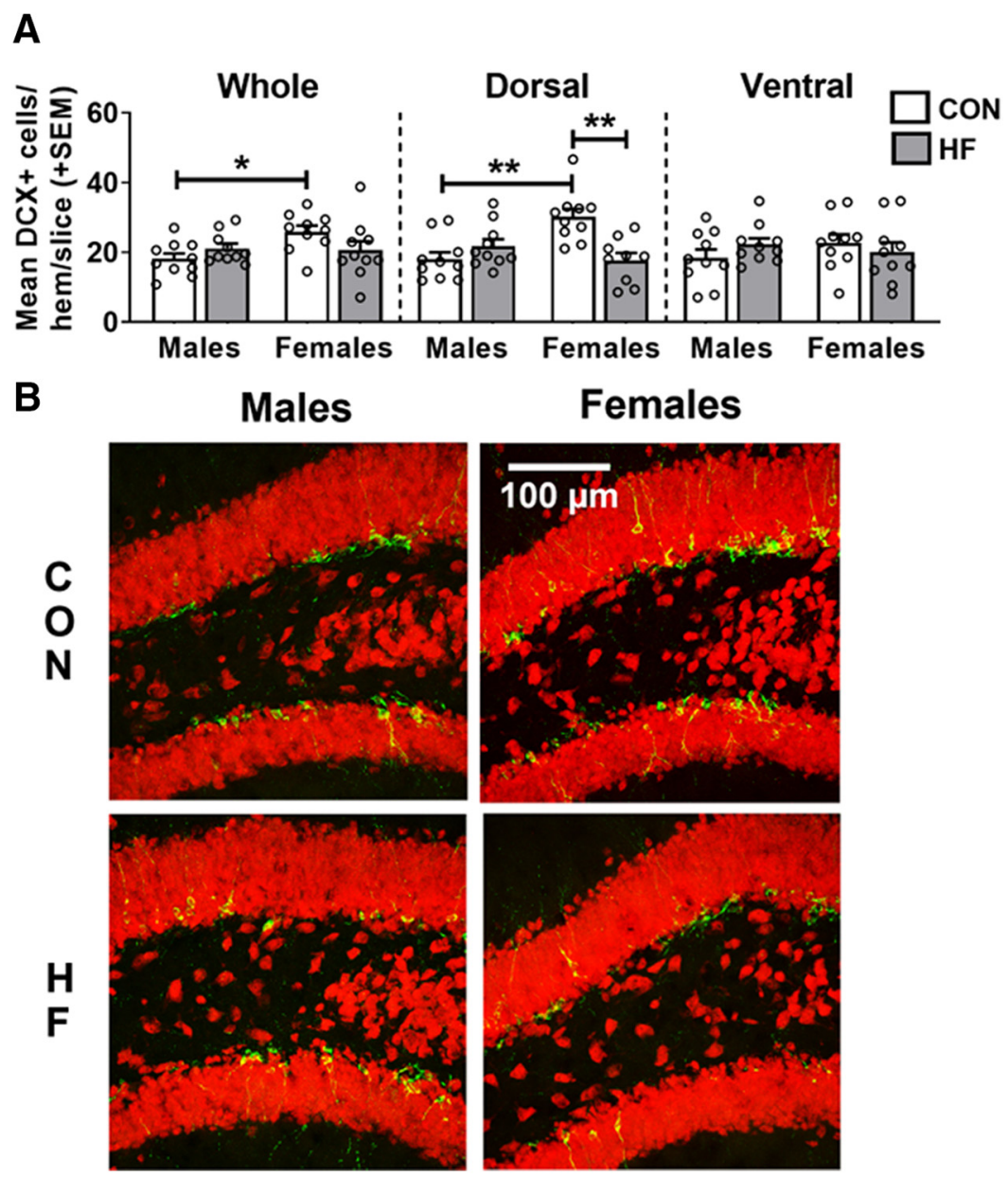

Figure 3. $\boldsymbol{A}$, Number of neuroblasts/immature neurons in the dentate gyrus, as measured by the mean $( \pm \mathrm{SEM})$ number of $\mathrm{DCX}^{+}$cells per hemisphere per $40 \mu \mathrm{m}$ slice throughout the whole hippocampus, and in the dorsal and ventral subregions. $\boldsymbol{B}$, On a CON diet, females had a greater number of $\mathrm{DCX}^{+}$cells in the dorsal hippocampus compared with males, while an HF diet reduced the number of $\mathrm{DCX}^{+}$cells in the dorsal hippocampus of females only. $N=10$ /group. $* p<0.05, * * p<0.01$. $\boldsymbol{B}$, Representative images of $\mathrm{DCX}$ (green) and NeuN (red) immunostaining in the dorsal hippocampus.

phase), and $\mathrm{EdU}^{+} / \mathrm{NeuN}^{+}$(newly born cells that differentiated into mature neurons; Fig. 4).

There was no significant effect of diet or sex on the number of $\mathrm{EdU}^{+}$cells or $\mathrm{EdU}^{+} / \mathrm{NeuN}^{+}$cells in the whole hippocampus, nor in the dorsal or ventral subregions. There were, however, significant group differences in the number of $\mathrm{EdU}^{+} / \mathrm{DCX}^{+}$cells. Although the diet $\times$sex interaction was significant in the whole hippocampus $(p=$ 0.0325), no pairwise comparisons reached statistical significance. In the dorsal hippocampus, females had a greater number of $\mathrm{EdU}^{+} / \mathrm{DCX}^{+}$cells compared with males overall $(p=0.016$; mean difference, $778.31 \%$; $95 \%$ $\mathrm{Cl}(156.63 \%, 1400.00 \%)]$, while no effect of diet was seen in this subregion. There was no significant effect of diet or sex on the number of $\mathrm{EdU}^{+} / \mathrm{DCX}^{+}$cells in the ventral hippocampus.

\section{Metabolic outcomes and neurogenesis are correlated in the dorsal hippocampus of females only}

Pearson correlations were run within each sex to assess the relationships between metabolic outcomes and neurogenesis measures in the whole hippocampus, and dorsal and ventral subregions. Correlations between metabolic outcomes [body weight gain and glucose intolerance (AUC during GTT test)] and the number of Ki67 ${ }^{+}$ cells (proliferating cells) and $\mathrm{DCX}^{+}$cells (neuroblasts/immature neurons) in the dorsal subregion of the hippocampus are shown in Figure 5.

In males, there were no significant associations between metabolic outcomes and neurogenesis measures in the whole hippocampus or in either hippocampal subregion. However, significant relationships between these measures were observed in females, indicating that worse metabolic outcomes were predictive of more severe impairments in hippocampal neurogenesis. In the whole hippocampus, only one significant negative correlation was found in females. Greater glucose intolerance (higher AUC during GTT) was associated with fewer Ki67 ${ }^{+}$cells ( $p$ $=0.037)$; this relationship was similarly seen in the ventral subregion $(p=0.016)$ in females. Metabolic outcomes appeared to be most strongly associated with neurogenesis in the dorsal subregion of females, with both weight gain and AUC during GTT inversely correlated with the 

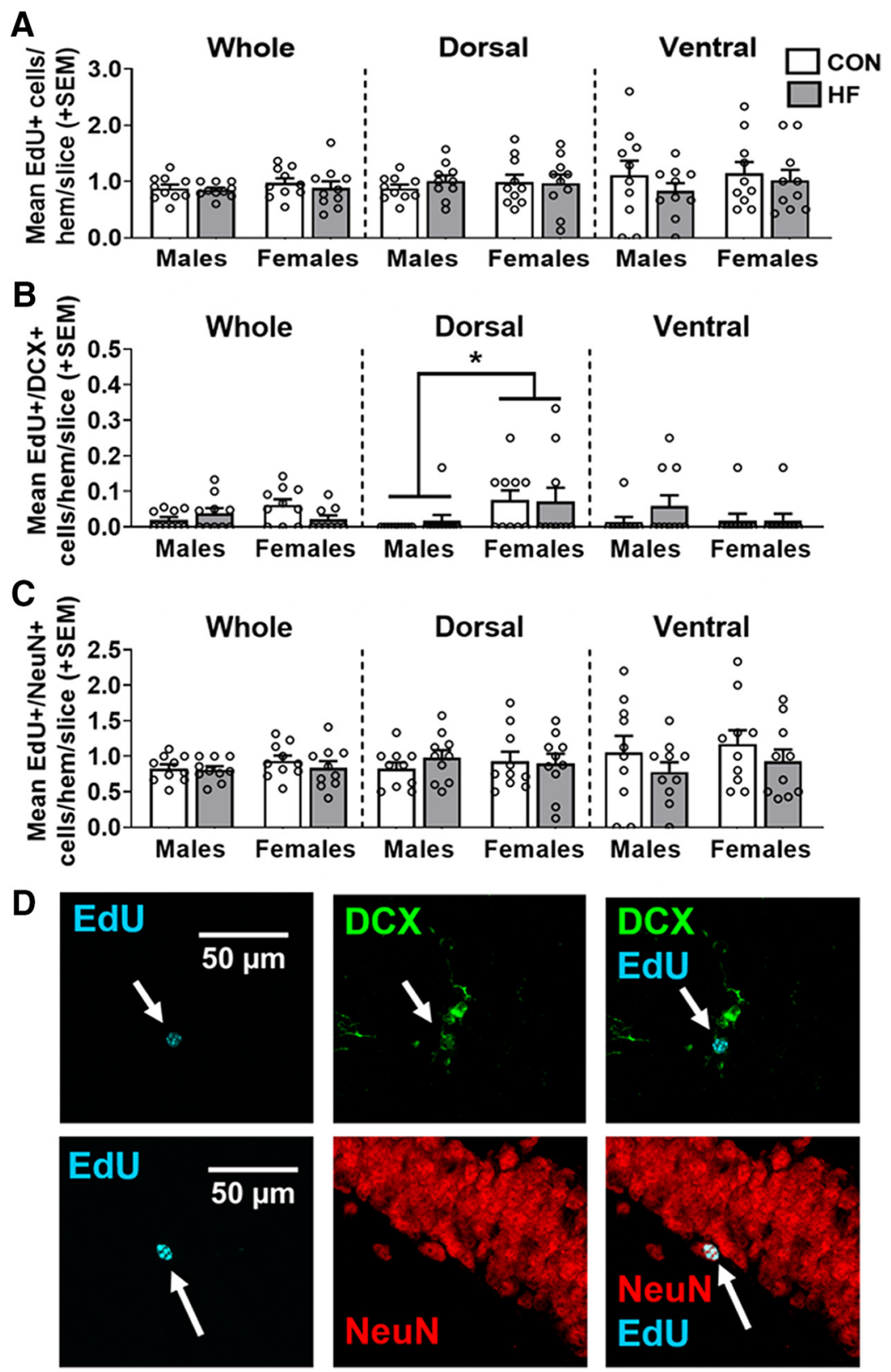

Figure 4. $\boldsymbol{A}$, Survival of newly born cells in the dentate gyrus, as measured by the mean $( \pm \mathrm{SEM})$ number of EdU ${ }^{+}$cells $28 \mathrm{~d}$ post-EdU injection throughout the whole hippocampus and in the dorsal and ventral subregions. There were no group differences in any area measured. $\boldsymbol{B}$, Newly born cells in the dentate gyrus that differentiated into neuroblasts/immature neurons and survived $28 \mathrm{~d}$ post-EdU injection, were measured by the mean $( \pm \mathrm{SEM})$ number of $\mathrm{EdU}^{+} / \mathrm{DCX}^{+}$cells throughout the whole hippocampus and in the dorsal and ventral subregions. In the dorsal hippocampus, females had a greater number of $\mathrm{EdU}^{+} / \mathrm{DCX}^{+}$cells compared with males, regardless of diet. $\boldsymbol{C}$, Newly born cells in the dentate gyrus that differentiated into mature neurons and survived $28 \mathrm{~d}$ post-EdU injection, were measured by the mean $\left( \pm\right.$ SEM) number of $\mathrm{EdU}^{+} / \mathrm{NeuN}^{+}$cells throughout the whole hippocampus and in dorsal and ventral subregions. There were no group differences in any area measured. $N=10 /$ group. $* p<0.05$ main effect of sex. $\boldsymbol{D}$, Representative images of EdU (cyan) alone and colocalized with DCX (green) and NeuN (red).

number of Ki67 $7^{+}$cells (weight gain, $p=0.028$; AUC during GTT, $p=0.008$ ) and $\mathrm{DCX}^{+}$cells (weight gain, $p=$ 0.003 ; AUC during GTT, $p=0.005)$. Metabolic outcomes were not significantly associated with the number of $\mathrm{EdU}^{+}, \mathrm{EdU}^{+} / \mathrm{DCX}^{+}$, or $\mathrm{EdU}^{+} / \mathrm{NeuN}^{+}$cells in the whole hippocampus, or either hippocampal subregion, in males or females (data not shown).
High-fat diet has sex-specific effects on microglia in the subgranular zone

Microglia play a multifaceted role in the neurogenic niche, regulating $\mathrm{AHN}$ by releasing growth factors and phagocytosing apoptotic newborn cells; additionally, microglia can adversely affect AHN under conditions that promote neuroinflammation (Aarum et al., 2003; Ekdahl 


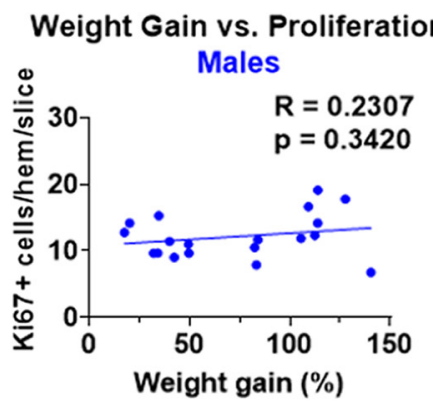

Glucose Tolerance vs. Proliferation
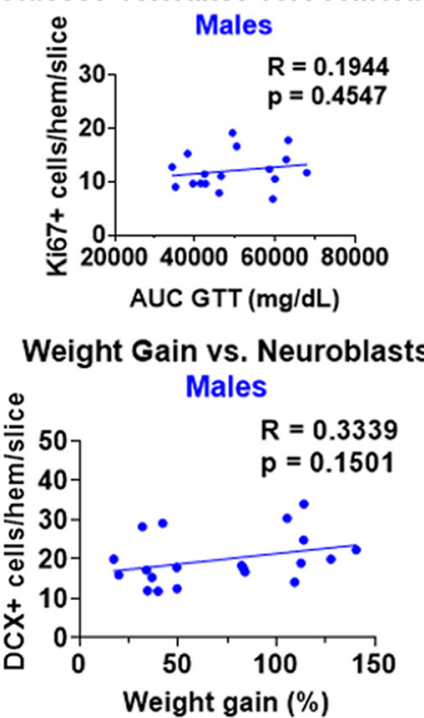

Glucose Tolerance vs. Neuroblasts

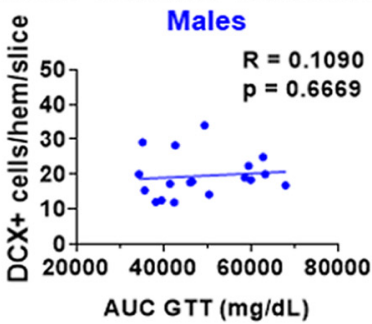

Weight Gain vs. Proliferation

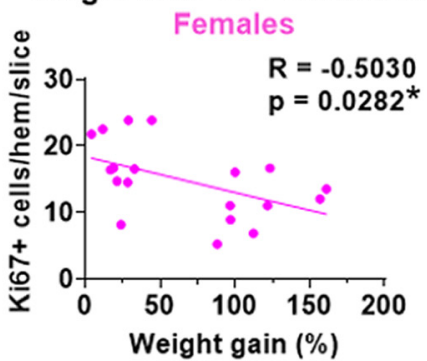

Glucose Tolerance vs. Proliferation

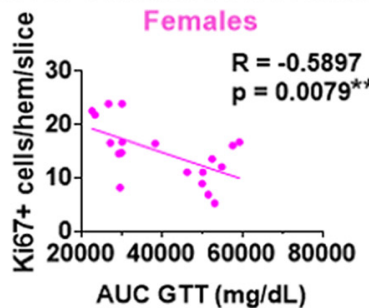

Weight Gain vs. Neuroblasts

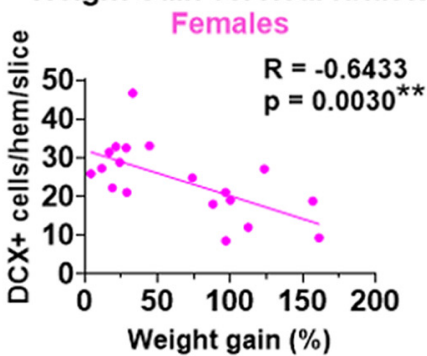

Glucose Tolerance vs. Neuroblasts

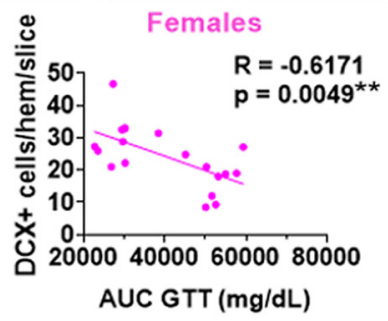

Figure 5. Correlations between metabolic outcomes [weight gain and glucose tolerance (AUC during GTT)] and neurogenesis measures [Ki67 ${ }^{+}$cells (proliferating cells) and $\mathrm{DCX}^{+}$cells (neuroblasts/immature neurons)] in the dorsal hippocampus of males (left) and females (right). Mice on both control and high-fat diet are included in these plots. Note the significant inverse associations between metabolic outcomes and neurogenesis in females, but not males. $N=20$ /sex. $* p<0.05, * * p<0.01$.

et al., 2003; Morgan et al., 2004; Ziv and Schwartz, 2008; De Lucia et al., 2016; Kreisel et al., 2019). Therefore, microglia activity was assessed in the inner and outer portions of the dentate gyrus of the hippocampus (Fig. 6), as microglia activity in these subregions could be differentially regulating neurogenesis (Gemma and Bachstetter, 2013; Rodríguez-Iglesias et al., 2019). Neurogenesis occurs in the subgranular zone, which was included in the inner region of the dentate. We assessed the percentage positive area for lba1 (microglia; Fig. $6 A, B$ ), CD68 (phagocytic marker; Fig. $6 C, D$ ), the percentage area of lba1 also positive for CD68 (relative degree of microglial phagocytic activity; Fig. $6 E, F)$, and the percentage area positive for colocalized Iba1 and CD68 (absolute microglial phagocytic activity; Fig. 6G,H).
In both the inner and outer areas of the dentate gyrus, and across the whole hippocampus and within dorsal and ventral subregions, $\mathrm{HF}$ diet increased $\mathrm{Iba} 1^{+}$area in males only $[p<0.05$ for all except outer ventral CON male vs HF male $(p=0.1137)$; mean differences ranging from $76.09 \%$ to $120.00 \%$; Fig. $6 A, B$ ). This also resulted in a significant sex difference within HF diet-fed mice (males $>$ females) in both the inner and outer areas of the dentate gyrus, across the whole hippocampus, and within the dorsal and ventral subregions ( $p<0.0 .05$ for all; mean differences ranging from $-63.14 \%$ to $-73.12 \%$; Fig. $6 A, B$ ).

Less pronounced trends, similar to $\mathrm{lba} 1^{+}$area, were seen for absolute microglial phagocytic activity (percentage area positive for colocalized Iba1 and CD68; Fig. $6 G, H)$. The area of positive staining was greater in $\mathrm{HF}$ 
INNER

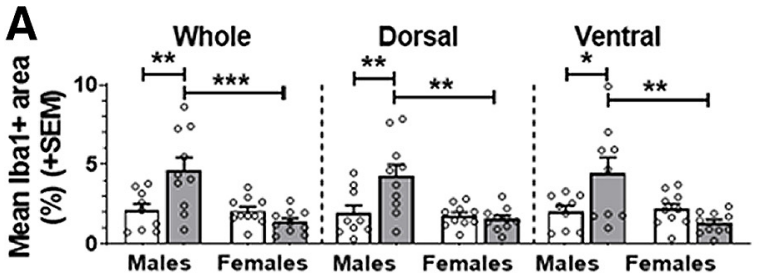

C

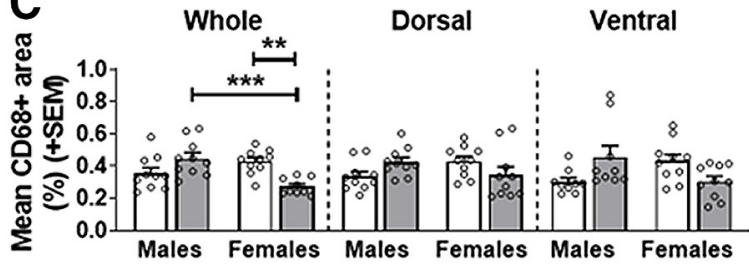

E

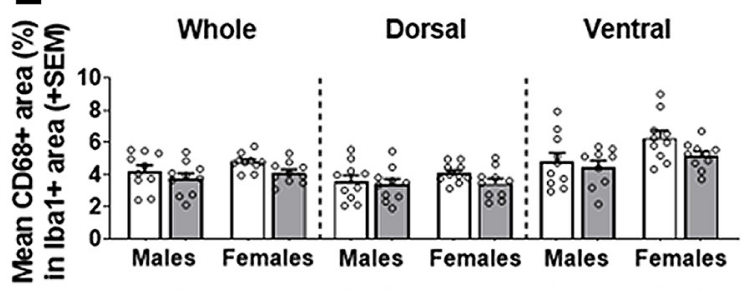

G

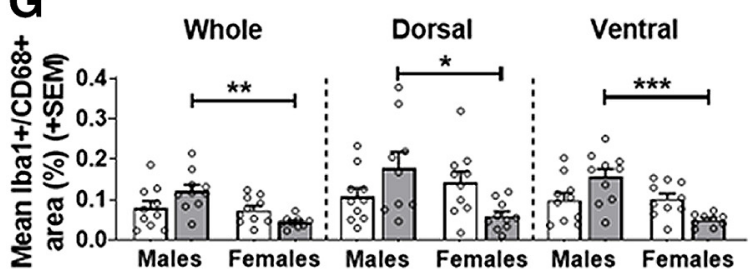

OUTER
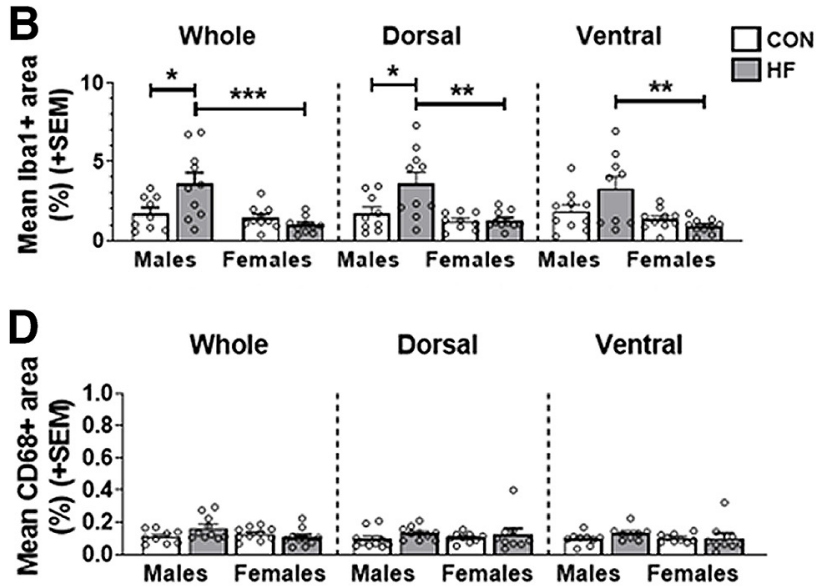

$\mathbf{F}$
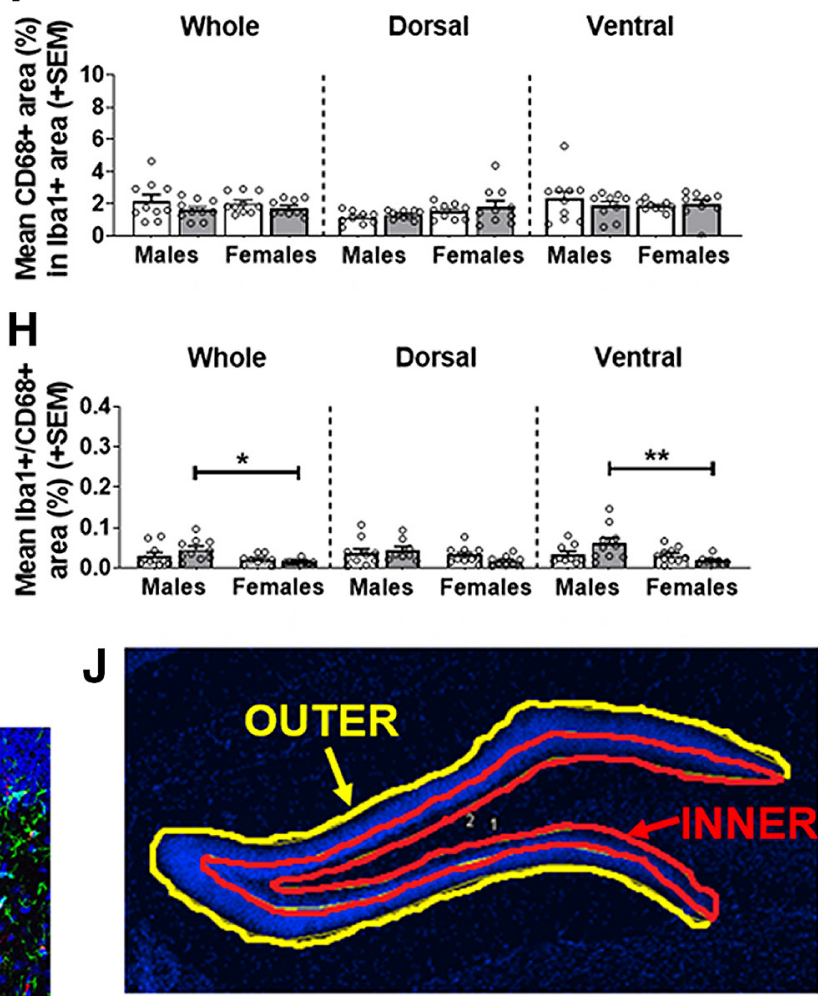

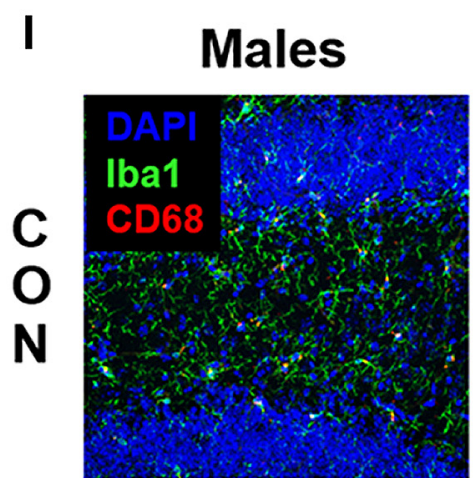

Females
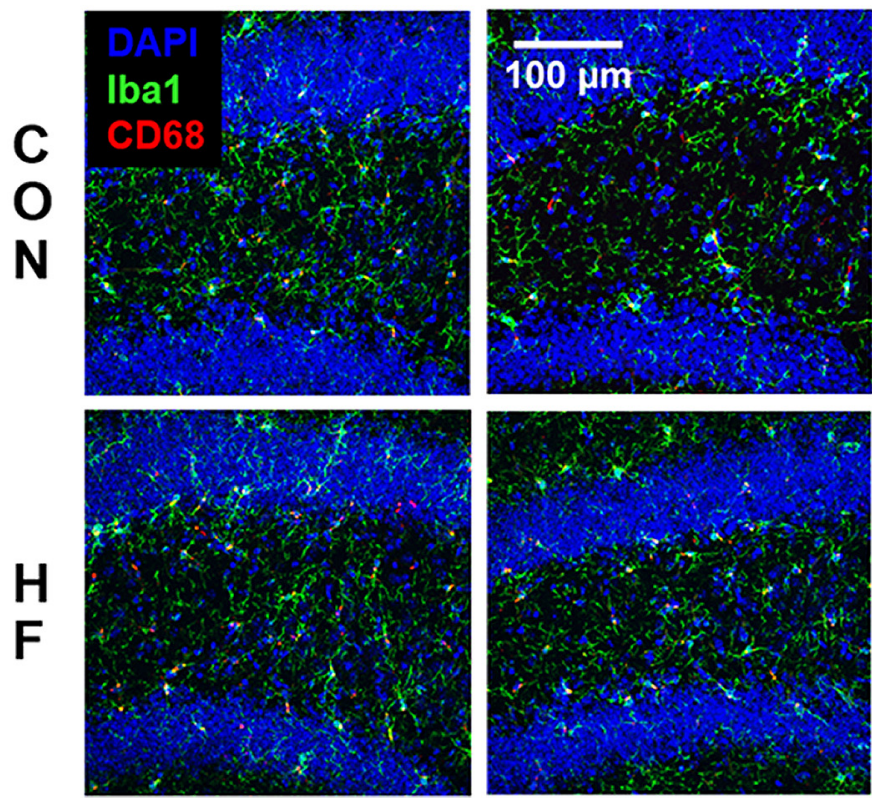

Figure 6. $\boldsymbol{A}, \boldsymbol{B}$, Microglia density in the inner $(\boldsymbol{A})$ and outer $(\boldsymbol{B})$ dentate, as measured by the mean $( \pm$ SEM) percentage area covered 
continued

by $\mathrm{Iba1}^{+}$stain throughout the whole hippocampus and in the dorsal and ventral subregions. $\boldsymbol{C}, \boldsymbol{D}$, Phagocytic activity in the inner $(\boldsymbol{C})$ and outer $(\boldsymbol{D})$ dentate, as measured by the mean ( + SEM) percentage area covered by $\mathrm{CD}^{+} \mathrm{s}^{+}$stain throughout the whole hippocampus and in the dorsal and ventral subregions. $\boldsymbol{E}, \boldsymbol{F}$, Relative degree of microglial phagocytic activity in the inner $(\boldsymbol{E})$ and outer $(\boldsymbol{F})$ dentate, as measured by the mean $\left( \pm\right.$ SEM) percentage of $\mathrm{Iba1} 1^{+}$area also positive for CD68 throughout the whole hippocampus and in the dorsal and ventral subregions. $\boldsymbol{G}, \boldsymbol{H}$, Absolute microglial phagocytic activity in the inner $(\boldsymbol{G})$ and outer $(\boldsymbol{H})$ dentate, as measured by the mean ( \pm SEM) percentage area positive for colocalized lba1 and CD68 throughout the whole hippocampus, and in the dorsal and ventral subregions. $N=10$ /group. $* p<0.05, * * p<0.01, * * * p<0.001$. I, Representative images of Iba1 ${ }^{+}$(green) and $\mathrm{CD68}^{+}$(red) cells in the dorsal dentate gyrus. DAPI (blue) counterstaining was used to visualize nuclei, determine position relative to bregma, and create ROIs around the dentate gyrus. J, Representative image of inner and outer ROls of the dentate gyrus. See Figure 6-1 for estimation statistics performed for microglia-related measures.

males compared with HF females in the whole, dorsal, and ventral hippocampus for the inner dentate, and in the whole hippocampus and ventral subregion for the outer dentate $(p<0.05$ for all; mean differences ranging from $-63.43 \%$ to $-70.61 \%)$.

In the inner portion of the dentate for the whole hippocampus, HF diet decreased the $\mathrm{CD}^{+} 8^{+}$area in females only $[p=0.0033$; mean difference, $-36.36 \%$; $95 \% \mathrm{Cl}(-16.78 \%,-55.93 \%)]$. Additionally, $\mathrm{HF} \mathrm{fe}-$ males had reduced $\mathrm{CD}^{+} 8^{+}$area compared with $\mathrm{HF}$ males $[p=0.0009$; mean difference, $-39.03 \% ; 95 \% \mathrm{Cl}$ $(-20.29 \%,-57.76 \%)$; Fig. 6B]. These trends were apparent but not significant in the dorsal and ventral subregions ( $p>0.05$ for all).

No differences between groups were observed for the percentage area of Iba1 also positive for CD68 (relative degree of microglial phagocytic activity; Fig. 6C).

\section{Microglia in the subgranular zone correlate with metabolic outcomes and neurogenesis in a sex- and region-specific manner}

Correlations between metabolic outcomes and microglia in the inner dentate gyrus were run separately by sex for the whole hippocampus and for dorsal and ventral subregions (Fig. 7). In males, metabolic outcomes (weight gain and AUC during GTT) were positively correlated with $\mathrm{Iba}^{+}$area in the whole, dorsal, and ventral subregions [p $<0.05$ for all except vs AUC during GTT in ventral subregion $(p=0.062)]$. There were also positive correlations in males between metabolic outcomes and $\mathrm{CD}^{+} 8^{+}$area, and metabolic outcomes with percentage area positive for colocalized Iba1 and CD68 (absolute microglial phagocytic activity) in the whole hippocampus and dorsal and ventral subregions $(r=0.32-0.49)$, though most of these relationships failed to reach statistical significance. In females, however, the opposite was seen, with metabolic outcomes negatively correlated with $\mathrm{Iba}^{+}$area, $\mathrm{CD}^{+} 8^{+}$ area, and the percentage area positive for colocalized Iba1 and CD68 (absolute microglial phagocytic activity), particularly in the ventral subregion. There tended to be a negative correlation between metabolic outcomes and the percentage area of Iba1 also positive for CD68 (relative degree of microglial phagocytic activity) in both males and females, though none of these associations reached statistical significance.

Correlations were also run between microglia and neurogenesis measures in the dentate gyrus, again performed separately by sex for the whole hippocampus and for dorsal and ventral subregions (Fig. 7). In males, both $\mathrm{CD} 68^{+}$area and the percentage area positive for colocalized Iba1 and CD68 (absolute microglial phagocytic activity) were positively correlated with the number of $\mathrm{Ki}^{+} 7^{+}$ cells in the whole hippocampus, and with both $\mathrm{Ki}_{6} 7^{+}$and $\mathrm{DCX}^{+}$cells in the ventral hippocampus ( $p<0.05$ for all); weaker, nonsignificant trends of the same direction were seen in the dorsal hippocampus. In females, both CD68 ${ }^{+}$ area and percentage area positive for colocalized Iba1 and CD68 (absolute microglial phagocytic activity) were positively correlated with the number of $\mathrm{Ki}^{+} 7^{+}$and $\mathrm{DCX}^{+}$ cells in the whole hippocampus and dorsal subregion, though most of these associations did not reach statistical significance; such correlations were not apparent in the ventral subregion in females ( $p>0.05$ for all). Microglia measures were not significantly associated with the number of $\mathrm{EdU}^{+}, \mathrm{EdU}^{+} / \mathrm{DCX}^{+}$, or $\mathrm{EdU}^{+} / \mathrm{NeuN}^{+}$cells in the whole hippocampus or in either hippocampal subregion in males or females (data not shown).

\section{Discussion}

The primary goal of this study was to determine whether there are sex differences in the effects of HF diet on $\mathrm{AHN}$ in mice. As previously reported, HF diet treatment from $\sim 2$ to 6 months of age results in males and females developing a prediabetic phenotype (weight gain and glucose intolerance) to a similar degree of severity in both sexes (Salinero et al., 2018). The major finding of this study is that HF diet adversely affects AHN in a sex-, stage-, and subregion- specific manner. Specifically, we found that HF diet decreases cell proliferation and the number of young/immature neurons in the dorsal subregion of the hippocampus of females only. Moreover, within females, the degree of metabolic impairment was associated with greater neurogenic deficits. We also assessed the effects of HF diet on microglia activity in the dentate gyrus as a possible mechanism of sex-specific changes in neurogenesis. We uncovered sex-specific effects of HF diet on microglia, as well as relationships between microglia activity and neurogenesis, which suggest that an increased presence of microglia may be protective against decreases in neurogenesis in the presence of metabolic disease.

\section{Sex differences in neurogenesis in metabolically healthy mice}

We found that in metabolically healthy animals fed a control diet, females exhibit greater levels of cell prolifer- 
MALES
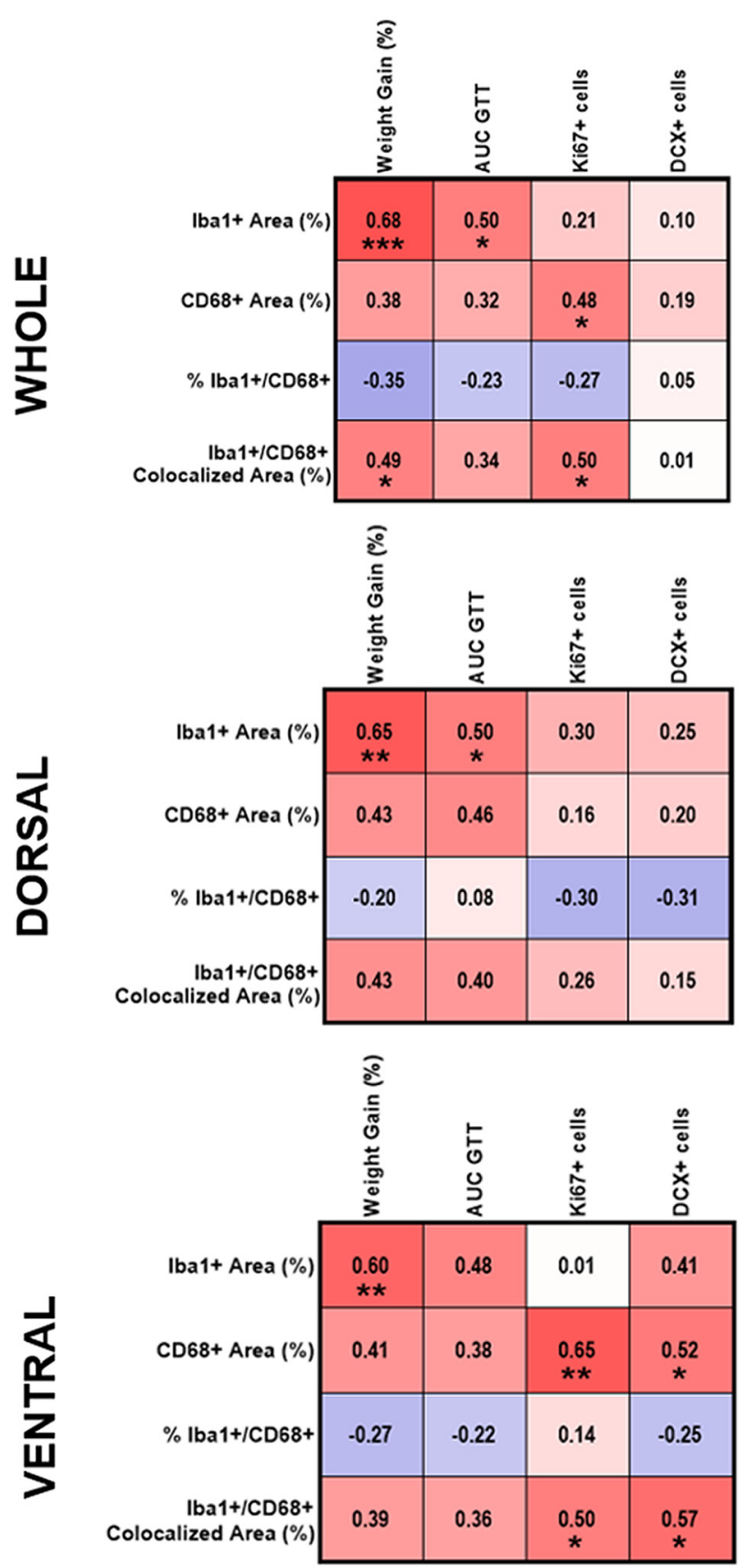

FEMALES
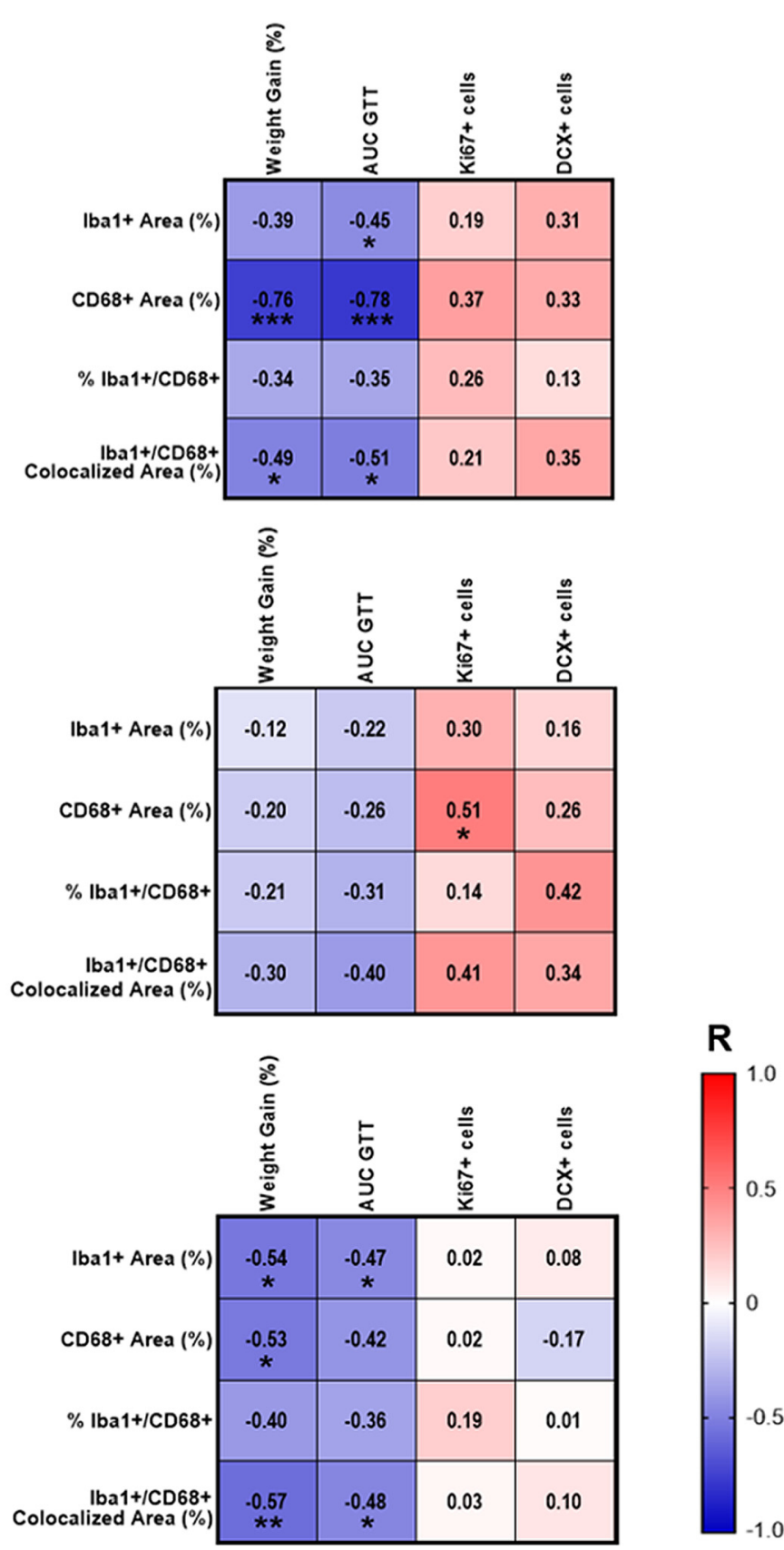

Figure 7. Correlations of microglia measures in the inner dentate with metabolic outcomes and neurogenesis in the whole hippocampus, and in dorsal and ventral subregions of male (left) and female (right) mice. Red indicates positive correlations, and blue indicates negative correlations, with intensity of the color indicative of the strength of the association. $* p<0.05, * * p<0.01$.

ation (Ki67 ${ }^{+}$cells) and more neuroblasts/immature neurons $\left(\mathrm{DCX}^{+}\right.$cells). These findings are in agreement with previous studies reporting that female rodents have greater proliferation, which may depend on season or cycle of the estrus phase, compared with males (Galea and McEwen, 1999; Tanapat et al., 1999; Spritzer et al., 2017), though a previous study found that male rats had a greater number of immature neurons compared with females (Hillerer et al., 2013). Observed sex differences may be mediated at least in part by sex hormones, as estradiol treatment has been shown to increase proliferation in both intact and ovariectomized female rats (Tanapat et al., 1999; Duarte-Guterman et al., 2015). Additionally, proliferation varies throughout the estrus cycle, with levels of proliferation greatest during the proestrus phase when estradiol levels are highest (Tanapat et al., 1999), though some have failed to show sex differences or estrus cycle effects on proliferation in mice (Amrein et al., 2004; 
Lagace et al., 2007). As we did not monitor the estrus cycle, we cannot speculate whether this played a role in the observed increase in cell proliferation and the number of neuroblasts/immature neurons in control diet-fed females compared with males.

While the number of young/immature neurons was greater in females compared with males, there was no difference in the number of surviving mature neurons $\left(\mathrm{EdU}^{+} / \mathrm{NeuN}^{+}\right.$cells) in the dentate gyrus. Lack of sex differences in new neuron survival has been reported in previous work in rodents (Tanapat et al., 1999; Barker and Galea, 2008; Spritzer et al., 2017). These findings could be explained either by a higher rate of death of newly born cells or by neurons remaining in an immature state in females. The former possibility is supported by previous findings that female rats exhibit greater degeneration (pyknotic cells) in the SGZ and granule cell layer compared with males throughout most of the estrus cycle, and no sex difference in BrdU-labeled cell survival or total number of granule neurons in the dentate gyrus (Tanapat et al., 1999). The latter possibility is supported by our findings that females (regardless of diet) exhibited a greater number of $\mathrm{EdU}^{+} / \mathrm{DCX}^{+}$cells in the dentate gyrus compared with males, representative of 4-week-old cells that still remained in a neuroblast/immature neuron state. As neurons reach maturation, they trade expression of DCX for mature neuron markers such as NeuN. It was previously shown in mice that at 4 weeks post-BrdU injection (time equivalent to our observed time point), $\sim 50 \%$ of the cells are $\mathrm{NeuN}^{+}$and $\sim 30 \%$ are $\mathrm{DCX}^{+}$; however, this study was performed in male mice only (Snyder et al., 2009). It is possible that maturation of neurons may occur more slowly in females compared with males, as suggested by a recent study in rats (Yagi et al., 2019). There is evidence to suggest that immature neurons may be functionally relevant (see discussion below), and their contribution to observed sex differences in hippocampal-dependent cognitive strategies and performance (Yagi and Galea, 2019) warrant future study.

\section{Sex differences in the effects of high-fat diet/prediabetes on adult hippocampal neurogenesis}

The current study found that an HF diet decreased cell proliferation and the number of neuroblasts/immature neurons in the dentate gyrus of females, while males were unaffected by diet. Additionally, there were strong negative associations between metabolic dysfunction (weight gain and glucose intolerance) and these measures of neurogenesis in females. These correlations were not seen in males, as expected, due to lack of diet effect. Previous studies have found that high-fat diet and metabolic disease such as obesity and diabetes disturb several aspects of neurogenesis. For example, mice administered a high-fat diet show impaired neurogenesis and decreased BDNF, as well as increased lipid peroxidation (Park et al., 2010). Similarly, administration of a high-fat diet for 8 weeks beginning at 6 weeks of age to male C57BL6/J mice resulted in increased body mass and fasting blood glucose levels, in addition to reduced BDNF and number of $\mathrm{Ki}^{+} 7^{+}, \mathrm{DCX}^{+}$, and $\mathrm{BrdU}^{+}$cells in the dentate gyrus of the hippocampus (Nam et al., 2017). It is important to note that initiating the diet early ( 6 weeks of age) in males elicits a type 2 diabetic phenotype, in contrast to our current study in which diet was initiated at 8 weeks of age and resulted in a prediabetic phenotype. Genetic and pharmacological rodent models of diabetes also demonstrate impaired neurogenesis, including reductions in Ki67 and DCX in the dentate (JacksonGuilford et al., 2000; Yi et al., 2009; Chung et al., 2015; Yau et al., 2018). Our findings contrast with those of one of the first studies on HF diet in juvenile Sprague Dawley rats, which found that 4 weeks of eating a high-fat diet reduced hippocampal neurogenesis (number of $\mathrm{BrdU}^{+}$ cells 2 weeks postinjection) by $\sim 40 \%$ in males in the absence of obesity; however, while an HF diet increased weight gain and adiposity in females, no effect on neurogenesis was apparent (Lindqvist et al., 2006). Only weight gain and fat mass were assessed in these rats, while their glucose tolerance/diabetic status is unknown. The negative influences of an HF diet on Ki67 and DCX have been demonstrated in male mice of other strains (Hwang et al., 2008). Other studies using male C57BL/6J mice failed to show any differences in DCX when HF diet was started in adulthood (12 weeks of age; Boitard et al., 2012), similar to our own findings. Sex differences in the susceptibility of adult hippocampal neurogenesis with other exogenous factors, such as stress, learning, and exercise, have been noted (Falconer and Galea, 2003; Dalla et al., 2009; Chow et al., 2013; Hillerer et al., 2013; Yagi et al., 2016; Cahill et al., 2018). For example, one study found that chronic restraint stress during adolescence was found to attenuate cell proliferation and survival in adult female but not male rats (Barha et al., 2011). The extent to which these sex differences are mediated by sex hormones remains to be determined. As discussed, estradiol and estrus cycle phase affect neurogenesis (Tanapat et al., 1999; DuarteGuterman et al., 2015), and diet induced-obese female mice have been shown to exhibit estrus cycle abnormalities and altered levels of sex hormones and enzymes involved in steroidogenesis (Lai et al., 2014; Wu et al., 2014; Hohos et al., 2018). Recent evidence also suggests that estrogen receptor (ER)- $\alpha$ and/or ER- $\beta$ play a role in type 2 diabetes-induced impairments in neurogenesis and cognitive function in mice (Tang et al., 2019).

The hippocampus is a heterogeneous structure, with the dorsal subregion (septal pole) functionally distinct from the ventral subregion (temporal pole), corresponding to the human posterior and anterior portions of the hippocampus, respectively. The dorsal hippocampus is implicated in cognitive processes, including spatial learning and memory, while the ventral hippocampus is involved in affective processes, such as emotion regulation and stress reactivity (O'Leary and Cryan, 2014). In addition to behavior studies, there is evidence for this heterogeneity based on gene expression and anatomic connectivity (O'Leary and Cryan, 2014). While the dorsal hippocampus is connected to brain regions involved in visuospatial processing, spatial navigation/exploration, and spatial memory (e.g., anterior cingulate cortex, retrosplenial cortex, mammillary nuclei), the ventral hippocampus appears 
to communicate with regions involved in neuroendocrine function, stress, anxiety, reward, motivation, and executive function (e.g., hypothalamus, amygdala, nucleus accumbens, and medial prefrontal cortex; O'Leary and Cryan, 2014). Despite the fact that the segregation of the dorsal and ventral subregions has been generally accepted, few have assessed neurogenesis in these two subregions separately. However, previous studies that have examined the effects of environmental factors on neurogenesis in the dorsal and ventral subregions separately have often found that manipulations preferentially affect facets of neurogenesis in one subregion versus the other (Tanti et al., 2012, 2013; O'Leary and Cryan, 2014). For example, unpredictable chronic mild stress decreased proliferation and neurogenesis preferentially in the ventral hippocampus, while environmental enrichment increased proliferation in both subdivisions but increased neurogenesis in the dorsal hippocampus only (Tanti et al., 2012). Interestingly, the current study suggests that a high-fat diet and the resulting metabolic dysfunction preferentially disturb neurogenic processes in the dorsal subregion of the hippocampus, and that this occurs in females only. Our findings of HF diet-induced disruption of neurogenic processes in the dorsal hippocampus are in agreement with studies that have shown that HF diet impairs cognitive function that is dependent on this subregion of the hippocampus (Cordner and Tamashiro, 2015), such as performance on the latent cue preference task or the conditioned cue preference task in a multiplecue environment, while other forms of learning are spared (Stouffer et al., 2015).

While we did not observe an effect of diet on the long-term (4 week) survival of newly born neurons in either sex, high-fat diet/metabolic dysfunction-induced decreases in cell proliferation and, particularly, the number of young/immature neurons may be functionally significant. It has been shown that new cells in the dentate gyrus can extend their axons into the CA3 region as early as 4-10 days post-BrdU incorporation (Hastings and Gould, 1999). This suggests that, even at an immature stage, these cells may have a functional impact. This is further supported by evidence that young/immature neurons contribute a form of LTP in the hippocampus that is distinct (lower threshold, longer-lasting, weaker GABAergic inhibition) from that supported by more mature neurons (Wang et al., 2000; Snyder et al., 2001). These neuroblasts/immature neurons are implicated in longterm spatial memory, while more mature neurons are hypothesized to support acquisition and short-term retention (Snyder et al., 2005). Therefore, the effects of diet and metabolic dysfunction on the production and/or maintenance of immature neurons may have significant implications for hippocampal structure and function in females. We are currently investigating whether HF diet/prediabetes causes greater impairments in dorsal hippocampusdependent spatial memory tasks (e.g., Morris water maze) in females compared with males in mouse models of healthy aging and dementia.

\section{Sex differences in the effects of high-fat diet/prediabetes on microglia activity and relation to neurogenesis}

We sought to determine whether the adverse effects of HF diet on neurogenesis in females could be due to increased neuroinflammation mediated by microglia, the resident immune cell of the brain. We hypothesized that this could be the case based on previous findings that high-fat diet/metabolic disease are associated with increased inflammation, including microglia activity in the hippocampus (Kang et al., 2016; Ledreux et al., 2016; Yu et al., 2019), and that microglial-associated inflammation (i.e., via release of inflammatory cytokines such as IL-1 $\beta$, TNF- $\alpha$, and IL-6) impairs AHN in rodents (Ekdahl et al., 2003; Monje et al., 2003). Our results indicate that while there were no sex differences in microglia measures in mice on a control diet, we uncovered sex-specific effects of HF diet on microglia in the dentate gyrus. We focused on the inner dentate gyrus, which included the subgranular zone, as this is the region where proliferating cells $\left(\mathrm{Ki}^{+} 7^{+}\right)$and young/immature neurons $\left(\mathrm{DCX}^{+}\right)$are found, and these were the cells affected by an HF diet. However, many findings were similar though less robust in the outer dentate. We found that HF diet increased the area of the dentate gyrus covered by microglia $\left(\mathrm{lba}^{+}\right)$, an effect that was consistent across the entire region; however, this occurred in males only. There was no increase in microglial measures in females on an HF diet; in fact, trends fell in the opposite direction. Sex differences are also demonstrated by positive correlations between metabolic outcomes and microglia measures in males, and negative relationships between these measures in females.

In addition to microglia-mediated neuroinflammation having adverse effects on $\mathrm{AHN}$, there are several mechanisms by which microglia support AHN (Ziv and Schwartz, 2008), enhancing proliferation, neuronal differentiation, migration, and survival (Aarum et al., 2003; Morgan et al., 2004; Walton et al., 2006). In fact, microglia appear to be essential for the survival of neuroblasts (Kreisel et al., 2019), while inhibiting microglia activity with minocycline treatment attenuates AHN (Ziv et al., 2006). Microglia produce neuroprotective factors such as FGF-2, IGF-1, and BDNF that likely contribute to their proneurogenic effects (Ziv and Schwartz, 2008). Additionally, interventions like environmental enrichment, which have been shown to enhance hippocampal BDNF, increase microglial activation and $\mathrm{Iba}^{+}$expression in the dentate (but not in CA1 or CA3), suggesting that microglia activity may play a positive role in supporting neurogenic processes (Williamson et al., 2012). Moreover, enhanced neurogenesis observed in some cases following brain insult or disease may be mediated by activated microglia (Liu et al., 1998; Ogita et al., 2012; De Lucia et al., 2016). It is possible that the enhanced microglia markers observed in HF-fed males is neuroprotective, as HF males do not experience detrimental effects of diet on neurogenesis. HF diet-induced deficits in cell proliferation and young/ immature neurons in females are not accompanied by similarly increased measures of microglia markers; in fact, the opposite is observed. 
Microglia also play a role in phagocytosing apoptotic cells in the dentate gyrus, as many proliferating and young neurons do not survive into maturity; this process protects against the spilling of toxic cellular contents from apoptotic cells (Gemma and Bachstetter, 2013; Sato, 2015). Negative correlations between metabolic outcomes with microglia and phagocytic markers in females, associated with dysregulated neurogenesis, may therefore represent sex-specific impairments in microglia function. Impairments of hippocampal microglia phagocytic capability have been demonstrated in response to other environmental influences (e.g., inescapable stress), which appear to be more severe in females compared with males (Fonken et al., 2018). There are also known sex differences across normal development and aging in microglia in several brain structures, as well as sex-mediated expression of cytokines and chemokines in regions such as the cortex and hippocampus (Schwarz and Bilbo, 2012; Schwarz et al., 2012; Kopec et al., 2018). However, further investigation is necessary to investigate sex differences in the role of microglia in AHN under pathophysiological conditions, including metabolic disease.

\section{Conclusions}

In the current study, we found that chronic administration of a high-fat diet from $\sim 2$ to 6 months of age produces striking sex differences in its consequences on adult hippocampal neurogenesis. Cell proliferation, neuroblasts, and new neuron maturation and survival were unaffected by diet in males. In females, however, high-fat diet significantly reduced cell proliferation and the number of young/immature neurons. Additionally, metabolic dysfunction was correlated with impaired neurogenesis in females only. These effects of diet and metabolic impairment on neurogenesis were robust in the dorsal hippocampus, which plays a role in cognitive functions like learning and memory (Fanselow and Dong, 2010; Kheirbek and Hen, 2011). It was previously reported that this diet regimen results in a similar prediabetic phenotype (increased weight gain and glucose intolerance) in male and female C57BL6/J mice (Salinero et al., 2018). Therefore, the observed sex-specific effects of HF diet on neurogenesis are not likely attributable to sex differences in metabolic susceptibility to the diet. It was also recently reported that the metabolic effects of HF diet vary by age and sex, such that males experience greater metabolic impairment compared with females when diet begins as juveniles ( 6 weeks of age), but females experience greater weight gain and glucose intolerance compared with males when diet begins at middle age ( $\sim 8.5$ months; Salinero et al., 2018). It would be of interest to determine whether sex differences in AHN vary by age of diet onset as well, and how this relates to age- and sex-dependent effects of HF diet on metabolic outcomes.

Evidence suggests that detrimental diet effects may be reversible, as switching from the high-fat to the control diet is capable of restoring neurogenesis in rodents; however, this study was performed in male rats only (Boitard et al., 2016). Interventions that improve metabolic outcomes, such as physical exercise and caloric restriction, promote neurogenesis and gliogenesis, increase growth factors and synaptic plasticity in the hippocampus, and improve cognitive performance (Lee et al., 2002; Bondolfi et al., 2004; Park and Lee, 2011; Kaptan et al., 2015; Chatterjee et al., 2016; Klein et al., 2016). Moreover, treatment with medications traditionally used to treat type 2 diabetes increases adult hippocampal neurogenesis in HF diet-fed rodents (Hamilton et al., 2011; Porter et al., 2013; Pathak et al., 2015; Tanokashira et al., 2018). If adult hippocampal neurogenesis serves to preserve cognitive function during aging and neuropathology (e.g., AD pathology), but metabolic disease impairs neurogenesis, those with metabolic disease would be at increased risk for cognitive decline, particularly in women. This is of great clinical relevance, especially given the sex bias in dementia and $A D$ particularly (Hebert et al., 2013; Beam et al., 2018; Buckley et al., 2019). AD medications promote neurogenesis (Jin et al., 2006), and enhancing neurogenesis with genetic (Richetin et al., 2015), pharmacological (Blanchard et al., 2010), and behavioral (Valero et al., 2011; TapiaRojas et al., 2016) interventions rescues cognitive performance in $A D$ mouse models. Therefore, targeting metabolic disease or preventing/reversing its detrimental effects on hippocampal neurogenesis could reduce the burden of dementia in clinical populations, particularly women.

\section{References}

Aarum J, Sandberg K, Haeberlein SL, Persson MA (2003) Migration and differentiation of neural precursor cells can be directed by microglia. Proc Natl Acad Sci U S A 100:15983-15988.

Amrein I, Slomianka L, Poletaeva II, Bologova NV, Lipp HP (2004) Marked species and age-dependent differences in cell proliferation and neurogenesis in the hippocampus of wild-living rodents. Hippocampus 14:1000-1010.

Barha CK, Brummelte S, Lieblich SE, Galea LA (2011) Chronic restraint stress in adolescence differentially influences hypothalamic-pituitary-adrenal axis function and adult hippocampal neurogenesis in male and female rats. Hippocampus 21:1216-1227.

Barker JM, Galea LA (2008) Repeated estradiol administration alters different aspects of neurogenesis and cell death in the hippocampus of female, but not male, rats. Neuroscience 152:888-902.

Beam CR, Kaneshiro C, Jang JY, Reynolds CA, Pedersen NL, Gatz M (2018) Differences between women and men in incidence rates of dementia and Alzheimer's disease. J Alzheimers Dis 64:10771083.

Blanchard J, Wanka L, Tung YC, Cárdenas-Aguayo Mdel C, LaFerla FM, Iqbal K, Grundke-lqbal I (2010) Pharmacologic reversal of neurogenic and neuroplastic abnormalities and cognitive impairments without affecting $A \beta$ and tau pathologies in 3xTg-AD mice. Acta Neuropathol 120:605-621.

Boitard C, Etchamendy N, Sauvant J, Aubert A, Tronel S, Marighetto A, Layé S, Ferreira G (2012) Juvenile, but not adult exposure to high-fat diet impairs relational memory and hippocampal neurogenesis in mice. Hippocampus 22:2095-2100.

Boitard C, Cavaroc A, Sauvant J, Aubert A, Castanon N, Layé S, Ferreira G (2014) Impairment of hippocampal-dependent memory induced by juvenile high-fat diet intake is associated with enhanced hippocampal inflammation in rats. Brain Behav Immun 40:9-17.

Boitard C, Parkes SL, Cavaroc A, Tantot F, Castanon N, Layé S, Tronel S, Pacheco-Lopez G, Coutureau E, Ferreira G (2016) Switching adolescent high-fat diet to adult control diet restores neurocognitive alterations. Front Behav Neurosci 10:225. 
Boldrini M, Underwood MD, Hen R, Rosoklija GB, Dwork AJ, John Mann J, Arango V (2009) Antidepressants increase neural progenitor cells in the human hippocampus. Neuropsychopharmacology 34:2376-2389.

Bondolfi L, Ermini F, Long JM, Ingram DK, Jucker M (2004) Impact of age and caloric restriction on neurogenesis in the dentate gyrus of C57BL/6 mice. Neurobiol Aging 25:333-340.

Buck SB, Bradford J, Gee KR, Agnew BJ, Clarke ST, Salic A (2008) Detection of S-phase cell cycle progression using 5-ethynyl-2'deoxyuridine incorporation with click chemistry, an alternative to using 5-bromo-2'-deoxyuridine antibodies. Biotechniques 44:927929.

Buckley RF, Waller M, Masters CL, Dobson A (2019) To what extent does age at death account for sex differences in alzheimer's disease mortality rates? Am J Epidemiol 188:1213-1223.

Cahill SP, Cole JD, Yu RQ, Clemans-Gibbon J, Snyder JS (2018) Differential effects of extended exercise and memantine treatment on adult neurogenesis in male and female rats. Neuroscience 390:241-255.

Chan SW, Harmer CJ, Norbury R, O'Sullivan U, Goodwin GM, Portella MJ (2016) Hippocampal volume in vulnerability and resilience to depression. J Affect Disord 189:199-202.

Chatterjee S, et al. (2016) Type 2 diabetes as a risk factor for dementia in women compared with men: a pooled analysis of 2.3 million people comprising more than 100,000 cases of dementia. Diabetes Care 39:300-307.

Chow C, Epp JR, Lieblich SE, Barha CK, Galea LA (2013) Sex differences in neurogenesis and activation of new neurons in response to spatial learning and memory. Psychoneuroendocrinology 38:1236-1250.

Christie BR, Cameron HA (2006) Neurogenesis in the adult hippocampus. Hippocampus 16:199-207.

Chung JY, Yoo DY, Im W, Choi JH, Yi SS, Youn HY, Hwang IK, Seong JK, Yoon YS (2015) Electroacupuncture at the Zusanli and Baihui acupoints ameliorates type-2 diabetes-induced reductions in proliferating cells and differentiated neuroblasts in the hippocampal dentate gyrus with increasing brain-derived neurotrophic factor levels. J Vet Med Sci 77:167-173.

Cole J, Costafreda SG, McGuffin P, Fu CHY (2011) Hippocampal atrophy in first episode depression: a meta-analysis of magnetic resonance imaging studies. J Affect Disord 134:483-487.

Cordner ZA, Tamashiro KLK (2015) Effects of high-fat diet exposure on learning \& memory. Physiol Behav 152:363-371.

Dalla C, Papachristos EB, Whetstone AS, Shors TJ (2009) Female rats learn trace memories better than male rats and consequently retain a greater proportion of new neurons in their hippocampi. Proc Natl Acad Sci U S A 106:2927-2932.

De Lucia C, Rinchon A, Olmos-Alonso A, Riecken K, Fehse B, Boche D, Perry VH, Gomez-Nicola D (2016) Microglia regulate hippocampal neurogenesis during chronic neurodegeneration. Brain Behav Immun 55:179-190.

Demmer RT, Gelb S, Suglia SF, Keyes KM, Aiello AE, Colombo PC, Galea S, Uddin M, Koenen KC, Kubzansky LD (2015) Sex differences in the association between depression, anxiety, and type 2 diabetes mellitus. Psychosom Med 77:467-477.

Duarte-Guterman P, Lieblich SE, Chow C, Galea LA (2015) Estradiol and GPER activation differentially affect cell proliferation but not GPER expression in the hippocampus of adult female rats. PLoS One 10:e0129880.

Eid RS, Gobinath AR, Galea LAM (2019) Sex differences in depression: insights from clinical and preclinical studies. Prog Neurobiol 176:86-102.

Ekdahl CT, Claasen JH, Bonde S, Kokaia Z, Lindvall O (2003) Inflammation is detrimental for neurogenesis in adult brain. Proc Natl Acad Sci U S A 100:13632-13637.

Falconer EM, Galea LA (2003) Sex differences in cell proliferation, cell death and defensive behavior following acute predator odor stress in adult rats. Brain Res 975:22-36.

Fanselow MS, Dong H-W (2010) Are the dorsal and ventral hippocampus functionally distinct structures? Neuron 65:7-19.
Fonken LK, Frank MG, Gaudet AD, D'Angelo HM, Daut RA, Hampson EC, Ayala MT, Watkins LR, Maier SF (2018) Neuroinflammatory priming to stress is differentially regulated in male and female rats. Brain Behav Immun 70:257-267.

Galea LA, McEwen BS (1999) Sex and seasonal differences in the rate of cell proliferation in the dentate gyrus of adult wild meadow voles. Neuroscience 89:955-964.

Gannon OJ, Robison LS, Custozzo AJ, Zuloaga KL (2019) Sex differences in risk factors for vascular contributions to cognitive impairment \& dementia. Neurochem Int 127:38-55.

Gemma C, Bachstetter AD (2013) The role of microglia in adult hippocampal neurogenesis. Front Cell Neurosci 7:229-229.

Gould E, Beylin A, Tanapat P, Reeves A, Shors TJ (1999) Learning enhances adult neurogenesis in the hippocampal formation. Nat Neurosci 2:260-265.

Gutiérrez-Lobos K, Scherer M, Anderer P, Katschnig H (2002) The influence of age on the female/male ratio of treated incidence rates in depression. BMC Psychiatry 2:3.

Hamilton A, Patterson S, Porter D, Gault VA, Holscher C (2011) Novel GLP-1 mimetics developed to treat type 2 diabetes promote progenitor cell proliferation in the brain. J Neurosci Res 89:481-489.

Hastings NB, Gould E (1999) Rapid extension of axons into the CA3 region by adult-generated granule cells. J Comp Neurol 413:146154.

Hebert LE, Weuve J, Scherr PA, Evans DA (2013) Alzheimer disease in the United States (2010-2050) estimated using the 2010 census. Neurology 80:1778-1783.

Hill AS, Sahay A, Hen R (2015) Increasing adult hippocampal neurogenesis is sufficient to reduce anxiety and depression-like behaviors. Neuropsychopharmacology 40:2368-2378.

Hillerer KM, Neumann ID, Couillard-Despres S, Aigner L, Slattery DA (2013) Sex-dependent regulation of hippocampal neurogenesis under basal and chronic stress conditions in rats. Hippocampus 23:476-487.

Ho N, Sommers MS, Lucki I (2013) Effects of diabetes on hippocampal neurogenesis: links to cognition and depression. Neurosci Biobehav Rev 37:1346-1362.

Hohos NM, Cho KJ, Swindle DC, Skaznik-Wikiel ME (2018) High-fat diet exposure, regardless of induction of obesity, is associated with altered expression of genes critical to normal ovulatory function. Mol Cell Endocrinol 470:199-207.

Hwang IK, Kim IY, Kim DW, Yoo KY, Kim YN, Yi SS, Won MH, Lee IS, Yoon YS, Seong JK (2008) Strain-specific differences in cell proliferation and differentiation in the dentate gyrus of C57BL/6N and $\mathrm{C} 3 \mathrm{H} / \mathrm{HeN}$ mice fed a high fat diet. Brain Res 1241:1-6.

Irvine K, Laws KR, Gale TM, Kondel TK (2012) Greater cognitive deterioration in women than men with Alzheimer's disease: a meta analysis. J Clin Exp Neuropsychol 34:989-998.

Jacka FN, Pasco JA, Mykletun A, Williams LJ, Hodge AM, O'Reilly SL, Nicholson GC, Kotowicz MA, Berk M (2010) Association of Western and traditional diets with depression and anxiety in women. Am J Psychiatry 167:305-311.

Jackson-Guilford J, Leander JD, Nisenbaum LK (2000) The effect of streptozotocin-induced diabetes on cell proliferation in the rat dentate gyrus. Neurosci Lett 293:91-94.

Jin K, Xie L, Mao XO, Greenberg DA (2006) Alzheimer's disease drugs promote neurogenesis. Brain Res 1085:183-188.

Kang EB, Koo JH, Jang YC, Yang CH, Lee Y, Cosio-Lima LM, Cho JY (2016) Neuroprotective effects of endurance exercise against high-fat diet-induced hippocampal neuroinflammation. J Neuroendocrinol. Advance online publication. Retrieved December 14, 2019. doi:10.1111/jne.12385.

Kaptan Z, Akgün-Dar K, Kapucu A, Dedeakayoğulları H, Batu S, Üzüm G (2015) Long term consequences on spatial learningmemory of low-calorie diet during adolescence in female rats; hippocampal and prefrontal cortex BDNF level, expression of NeuN and cell proliferation in dentate gyrus. Brain Res 1618:194204. 
Kee N, Sivalingam S, Boonstra R, Wojtowicz JM (2002) The utility of $\mathrm{Ki}-67$ and $\mathrm{BrdU}$ as proliferative markers of adult neurogenesis. $\mathrm{J}$ Neurosci Methods 115:97-105.

Kempermann G, Song H, Gage FH (2015) Neurogenesis in the adult hippocampus. Cold Spring Harb Perspect Biol 7:a018812.

Kheirbek MA, Hen R (2011) Dorsal vs ventral hippocampal neurogenesis: implications for cognition and mood. Neuropsychopharmacology 36:373-374.

Klein C, Jonas W, Iggena D, Empl L, Rivalan M, Wiedmer P, Spranger J, Hellweg R, Winter Y, Steiner B (2016) Exercise prevents high-fat diet-induced impairment of flexible memory expression in the water maze and modulates adult hippocampal neurogenesis in mice. Neurobiol Learn Mem 131:26-35.

Knight EM, Martins IV, Gümüsgöz S, Allan SM, Lawrence CB (2014) High-fat diet-induced memory impairment in triple-transgenic Alzheimer's disease (3xTgAD) mice is independent of changes in amyloid and tau pathology. Neurobiol Aging 35:1821-1832.

Kopec AM, Smith CJ, Ayre NR, Sweat SC, Bilbo SD (2018) Microglial dopamine receptor elimination defines sex-specific nucleus accumbens development and social behavior in adolescent rats. Nat Commun 9:3769.

Kreisel T, Wolf B, Keshet E, Licht T (2019) Unique role for dentate gyrus microglia in neuroblast survival and in VEGF-induced activation. Glia 67:594-618.

Lagace DC, Fischer SJ, Eisch AJ (2007) Gender and endogenous levels of estradiol do not influence adult hippocampal neurogenesis in mice. Hippocampus 17:175-180.

Lai H, Jia X, Yu Q, Zhang C, Qiao J, Guan Y, Kang J (2014) High-fat diet induces significant metabolic disorders in a mouse model of polycystic ovary syndrome. Biol Reprod 91:127.

Ledreux A, Wang X, Schultzberg M, Granholm AC, Freeman LR (2016) Detrimental effects of a high fat/high cholesterol diet on memory and hippocampal markers in aged rats. Behav Brain Res 312:294-304.

Lee J, Duan W, Mattson MP (2002) Evidence that brain-derived neurotrophic factor is required for basal neurogenesis and mediates, in part, the enhancement of neurogenesis by dietary restriction in the hippocampus of adult mice. J Neurochem 82:13671375.

Lindqvist A, Mohapel P, Bouter B, Frielingsdorf H, Pizzo D, Brundin $P$, Erlanson-Albertsson C (2006) High-fat diet impairs hippocampal neurogenesis in male rats. Eur $\mathrm{J}$ Neurol 13:1385-1388.

Liu J, Solway K, Messing RO, Sharp FR (1998) Increased neurogenesis in the dentate gyrus after transient global ischemia in gerbils. J Neurosci 18:7768-7778.

Luppino FS, de Wit LM, Bouvy PF, Stijnen T, Cuijpers P, Penninx BW, Zitman FG (2010) Overweight, obesity, and depression: a systematic review and meta-analysis of longitudinal studies. Arch Gen Psychiatry 67:220-229.

McPherson S, Back C, Buckwalter JG, Cummings JL (1999) Genderrelated cognitive deficits in Alzheimer's disease. Int Psychogeriatr 11:117-122.

Miller BR, Hen R (2015) The current state of the neurogenic theory of depression and anxiety. Curr Opin Neurobiol 30:51-58.

Monje ML, Toda H, Palmer TD (2003) Inflammatory blockade restores adult hippocampal neurogenesis. Science 302:1760-1765.

Moreno-Jiménez EP, Flor-García M, Terreros-Roncal J, Rábano A, Cafini F, Pallas-Bazarra N, Ávila J, Llorens-Martin M (2019) Adult hippocampal neurogenesis is abundant in neurologically healthy subjects and drops sharply in patients with Alzheimer's disease. Nat Med 25:554-560.

Morgan SC, Taylor DL, Pocock JM (2004) Microglia release activators of neuronal proliferation mediated by activation of mitogenactivated protein kinase, phosphatidylinositol-3-kinase/Akt and delta-Notch signalling cascades. J Neurochem 90:89-101.

Nam SM, Kim JW, Yoo DY, Jung HY, Choi JH, Hwang IK, Seong JK, Yoon YS (2016) Reduction of adult hippocampal neurogenesis is amplified by aluminum exposure in a model of type 2 diabetes. $\mathrm{J}$ Vet Sci 17:13-20.
Nam SM, Kim JW, Kwon HJ, Yoo DY, Jung HY, Kim DW, Hwang IK, Seong JK, Yoon YS (2017) Differential effects of low- and highdose zinc supplementation on synaptic plasticity and neurogenesis in the hippocampus of control and high-fat diet-fed mice. Neurochem Res 42:3149-3159.

O'Leary OF, Cryan JF (2014) A ventral view on antidepressant action: roles for adult hippocampal neurogenesis along the dorsoventral axis. Trends Pharmacol Sci 35:675-687.

Ogita K, Yoneyama M, Hasebe S, Shiba T (2012) Activated microglial cells trigger neurogenesis following neuronal loss in the dentate gyrus of adult mice. Nihon Shinkei Seishin Yakurigaku Zasshi 32:281-285.

Park HR, Lee J (2011) Neurogenic contributions made by dietary regulation to hippocampal neurogenesis. Ann N Y Acad Sci 1229: 23-28.

Park HR, Park M, Choi J, Park KY, Chung HY, Lee J (2010) A high-fat diet impairs neurogenesis: involvement of lipid peroxidation and brain-derived neurotrophic factor. Neurosci Lett 482:235-239.

Pathak NM, Pathak V, Lynch AM, Irwin N, Gault VA, Flatt PR (2015) Stable oxyntomodulin analogues exert positive effects on hippocampal neurogenesis and gene expression as well as improving glucose homeostasis in high fat fed mice. Mol Cell Endocrinol 412:95-103.

Pedditzi E, Peters R, Beckett N (2016) The risk of overweight/obesity in mid-life and late life for the development of dementia: a systematic review and meta-analysis of longitudinal studies. Age Ageing 45:14-21.

Porter WD, Flatt PR, Hölscher C, Gault VA (2013) Liraglutide improves hippocampal synaptic plasticity associated with increased expression of Mash1 in ob/ob mice. Int J Obes (Lond) 37:678-684.

Richetin K, Leclerc C, Toni N, Gallopin T, Pech S, Roybon L, Rampon C (2015) Genetic manipulation of adult-born hippocampal neurons rescues memory in a mouse model of Alzheimer's disease. Brain 138:440-455.

Rodríguez-Iglesias N, Sierra A, Valero J (2019) Rewiring of memory circuits: connecting adult newborn neurons with the help of microglia. Front Cell Dev Biol 7:24.

Salinero AE, Anderson BM, Zuloaga KL (2018) Sex differences in the metabolic effects of diet-induced obesity vary by age of onset. Int J Obes (Lond) 42:1088-1091.

Santarelli L, Saxe M, Gross C, Surget A, Battaglia F, Dulawa S, Weisstaub N, Lee J, Duman R, Arancio O, Belzung C, Hen R (2003) Requirement of hippocampal neurogenesis for the behavioral effects of antidepressants. Science 301:805-809.

Sato K (2015) Effects of microglia on neurogenesis. Glia 63:13941405.

Schwarz JM, Bilbo SD (2012) Sex, glia, and development: interactions in health and disease. Horm Behav 62:243-253.

Schwarz JM, Sholar PW, Bilbo SD (2012) Sex differences in microglial colonization of the developing rat brain. J Neurochem 120: 948-963.

Shalev D, Arbuckle MR (2017) Metabolism and memory: obesity, diabetes, and dementia. Biol Psychiatry 82:e81-e83.

Snyder JS, Kee N, Wojtowicz JM (2001) Effects of adult neurogenesis on synaptic plasticity in the rat dentate gyrus. J Neurophysiol 85:2423-2431.

Snyder JS, Hong NS, McDonald RJ, Wojtowicz JM (2005) A role for adult neurogenesis in spatial long-term memory. Neuroscience 130:843-852.

Snyder JS, Choe JS, Clifford MA, Jeurling SI, Hurley P, Brown A, Kamhi JF, Cameron HA (2009) Adult-born hippocampal neurons are more numerous, faster maturing, and more involved in behavior in rats than in mice. J Neurosci 29:14484-14495.

Spauwen PJ, Köhler S, Verhey FR, Stehouwer CD, van Boxtel MP (2013) Effects of type 2 diabetes on 12-year cognitive change: results from the Maastricht Aging Study. Diabetes Care 36:15541561.

Spritzer MD, Panning AW, Engelman SM, Prince WT, Casler AE, Georgakas JE, Jaeger ECB, Nelson LR, Roy EA, Wagner BA (2017) Seasonal and sex differences in cell proliferation, neurogenesis, 
and cell death within the dentate gyrus of adult wild-caught meadow voles. Neuroscience 360:155-165.

Stouffer EM, Warninger EE, Michener PN (2015) A high-fat diet impairs learning that is dependent on the dorsal hippocampus but spares other forms of learning. Hippocampus 25:1567-1576.

Tanapat P, Galea LA, Gould E (1998) Stress inhibits the proliferation of granule cell precursors in the developing dentate gyrus. Int $\mathrm{J}$ Dev Neurosci 16:235-239.

Tanapat P, Hastings NB, Reeves AJ, Gould E (1999) Estrogen stimulates a transient increase in the number of new neurons in the dentate gyrus of the adult female rat. J Neurosci 19:5792-5801.

Tang SS, Ren Y, Ren XQ, Cao JR, Hong H, Ji H, Hu QH (2019) ER $\alpha$ and/or ER $\beta$ activation ameliorates cognitive impairment, neurogenesis and apoptosis in type 2 diabetes mellitus mice. Exp Neurol 311:33-43.

Tanokashira D, Kurata E, Fukuokaya W, Kawabe K, Kashiwada M, Takeuchi H, Nakazato M, Taguchi A (2018) Metformin treatment ameliorates diabetes-associated decline in hippocampal neurogenesis and memory via phosphorylation of insulin receptor substrate 1. FEBS Open Bio 8:1104-1118.

Tanti A, Belzung C (2013) Neurogenesis along the septo-temporal axis of the hippocampus: are depression and the action of antidepressants region-specific? Neuroscience 252:234-252.

Tanti A, Rainer Q, Minier F, Surget A, Belzung C (2012) Differential environmental regulation of neurogenesis along the septotemporal axis of the hippocampus. Neuropharmacology 63:374384.

Tanti A, Westphal WP, Girault V, Brizard B, Devers S, Leguisquet AM, Surget A, Belzung C (2013) Region-dependent and stage-specific effects of stress, environmental enrichment, and antidepressant treatment on hippocampal neurogenesis. Hippocampus 23:797811.

Tapia-Rojas C, Aranguiz F, Varela-Nallar L, Inestrosa NC (2016) Voluntary running attenuates memory loss, decreases neuropathological changes and induces neurogenesis in a mouse model of Alzheimer's disease. Brain Pathol 26:62-74.

Unger MS, Marschallinger J, Kaindl J, Höfling C, Rossner S, Heneka MT, Van der Linden A, Aigner L (2016) Early changes in hippocampal neurogenesis in transgenic mouse models for Alzheimer's disease. Mol Neurobiol 53:5796-5806.

Valero J, España J, Parra-Damas A, Martín E, Rodríguez-Álvarez J, Saura CA (2011) Short-term environmental enrichment rescues adult neurogenesis and memory deficits in APP(Sw,Ind) transgenic mice. PLoS One 6:e16832.

van Praag H, Kempermann G, Gage FH (1999) Running increases cell proliferation and neurogenesis in the adult mouse dentate gyrus. Nat Neurosci 2:266-270.

von Bohlen und Halbach O (2011) Immunohistological markers for proliferative events, gliogenesis, and neurogenesis within the adult hippocampus. Cell Tissue Res 345:1-19.

Walton NM, Sutter BM, Laywell ED, Levkoff LH, Kearns SM, Marshall GP 2nd, Scheffler B, Steindler DA (2006) Microglia instruct subventricular zone neurogenesis. Glia 54:815-825.
Wang L, Swank JS, Glick IE, Gado MH, Miller MI, Morris JC, Csernansky JG (2003) Changes in hippocampal volume and shape across time distinguish dementia of the Alzheimer type from healthy aging. Neuroimage 20:667-682.

Wang S, Scott BW, Wojtowicz JM (2000) Heterogenous properties of dentate granule neurons in the adult rat. J Neurobiol 42:248-257.

Westenbroek C, Den Boer JA, Veenhuis M, Ter Horst GJ (2004) Chronic stress and social housing differentially affect neurogenesis in male and female rats. Brain Res Bull 64:303-308.

Williamson LL, Chao A, Bilbo SD (2012) Environmental enrichment alters glial antigen expression and neuroimmune function in the adult rat hippocampus. Brain Behav Immun 26:500-510.

Wu S, Divall S, Nwaopara A, Radovick S, Wondisford F, Ko C, Wolfe A (2014) Obesity-induced infertility and hyperandrogenism are corrected by deletion of the insulin receptor in the ovarian theca cell. Diabetes 63:1270-1282.

Xu WL, Atti AR, Gatz M, Pedersen NL, Johansson B, Fratiglioni L (2011) Midlife overweight and obesity increase late-life dementia risk: a population-based twin study. Neurology 76:1568-1574.

Yagi S, Galea LAM (2019) Sex differences in hippocampal cognition and neurogenesis. Neuropsychopharmacology 44:200-213.

Yagi S, Chow C, Lieblich SE, Galea LA (2016) Sex and strategy use matters for pattern separation, adult neurogenesis, and immediate early gene expression in the hippocampus. Hippocampus 26:87101.

Yagi S, Splinter JEJ, Tai D, Wong S, Galea LAM (2019) Sex differences in maturation and attrition rate of adult born neurons in the hippocampus of rats. bioRxiv. Advance online publication. Retrieved December 14, 2019. doi:10.1101/726398.

Yau SY, Lee TH, Li A, Xu A, So KF (2018) Adiponectin mediates running-restored hippocampal neurogenesis in streptozotocininduced type 1 diabetes in mice. Front Neurosci 12:679.

Yi SS, Hwang IK, Yoo KY, Park OK, Yu J, Yan B, Kim IY, Kim YN, Pai T, Song W, Lee IS, Won MH, Seong JK, Yoon YS (2009) Effects of treadmill exercise on cell proliferation and differentiation in the subgranular zone of the dentate gyrus in a rat model of type II diabetes. Neurochem Res 34:1039-1046.

Yu M, Huang H, Dong S, Sha H, Wei W, Liu C (2019) High mobility group box-1 mediates hippocampal inflammation and contributes to cognitive deficits in high-fat high-fructose diet-induced obese rats. Brain Behav Immun 82:167-177.

Ziv Y, Schwartz M (2008) Immune-based regulation of adult neurogenesis: implications for learning and memory. Brain Behav Immun 22:167-176.

Ziv Y, Ron N, Butovsky O, Landa G, Sudai E, Greenberg N, Cohen H, Kipnis J, Schwartz M (2006) Immune cells contribute to the maintenance of neurogenesis and spatial learning abilities in adulthood. Nat Neurosci 9:268-275.

Zuloaga KL, Johnson LA, Roese NE, Marzulla T, Zhang W, Nie X, Alkayed FN, Hong C, Grafe MR, Pike MM, Raber J, Alkayed NJ (2016) High fat diet-induced diabetes in mice exacerbates cognitive deficit due to chronic hypoperfusion. J Cereb Blood Flow Metab 36:1257-1270. 